\title{
Tailoring the Structural, Morphological, Electrochemical, and Dielectric Properties of Solid Polymer Electrolyte
}

\author{
Anil Arya, A. L. Sharma* \\ Department of Physical Sciences, Central University of Punjab, Bathinda-151001, Punjab, INDIA \\ Corresponding Author E-Mail: alsharma@cup.edu.in
}

\begin{abstract}
:
Herein, we present preparation of solid polymer electrolyte (SPE) comprising of PEO, $\mathrm{NaPF}_{6}$ and varying fraction of Succinonitrile $(\mathrm{SN})$ by standard solution cast technique. The morphological features and structural properties were studied by the FESEM, XRD, respectively. FTIR was performed to study the interactions between polymer host, salt, and SN. Impedance spectroscopy, Transference number measurements, LSV and CV were used to examine the electrochemical properties. The complex permittivity/conductivity \& modulus were studied to understand the dielectric properties by evaluating the dielectric strength, relaxation time, hopping frequency and dc conductivity. Based on the experimental results an interaction mechanism is presented.
\end{abstract}

Key Words: Solid polymer electrolyte, X-Ray Diffraction, Ionic conductivity, Relaxation Time

\section{Introduction}

The Lithium-ion batteries (LIB) are the most fascinating candidate for the portable electronics, electric vehicles since its commercialization in 1991 by SONY corporation. The LIB possess advantages such as high energy density, long cycle life but some drawback restricts its use i.e. high cost, less abundant and environmental impact. Sodium ion battery (SIB) is an excellent alternative to the LIB and convey subsequent advantages over LIB; (i) Na is highly abundant, (ii) Low cost, and (iii) suitable redox potential $\left(\mathrm{E}_{\mathrm{Na}^{+}+\mathrm{Na}}^{\mathrm{O}}=-2.71 \mathrm{~V}\right.$ versus standard hydrogen electrode; only $0.3 \mathrm{~V}$ above that of lithium) [1-4].

The development of polymer electrolyte (PEs) in order to substitute the traditional liquid electrolyte for energy storage devices (eg. Battery, supercapacitor etc.) has attracted the widespread attention of scientific community due to advantages such as safety, flexibility, varied shape geometry, good interfacial compatibility. The first report proposed by Wright \& Co-workers in 1973 comprising of PEO and alkali metals salt motivated them to use as an electrolyte in the batteries. But, low ionic conductivity at ambient temperature was one of constraint to use them in practical applications. So, new materials were developed by incorporating low molecular weight plasticizers in polymer salt matrix known as gel polymer electrolytes (GPEs). Although the GPEs 
have comparable ionic conductivity $\left(10^{-3} \mathrm{~S} \mathrm{~cm}^{-1}\right)$ to the liquid electrolyte the poor mechanical strength/safety and liquid plasticizer prevent their use as an electrolyte in the commercial applications. To overcome the above issues a solvent-free system was i.e. solid polymer electrolyte (SPE) was launched and has gained momentous research interest as a promising alternative to liquid/gel polymer electrolyte which has drawbacks such as; flammability, leakage issue and bulky in size. One key advantage with SPE is that it plays a dual role, (i) work as a separator as well as electrolyte, and (ii) act as a binder to improve the interfacial contact with electrodes. However, SPE possesses lower ionic conductivity at ambient temperature. To overcome the poor ionic conductivity various approaches are manifested to develop new materials such as polymer blending, nanofiller dispersion, incorporation of ionic liquids/plasticizer [5-16].

Poly (ethylene oxide) is the most popular candidate among all polymers due to its interesting characteristics, low glass transition temperature, the presence of electron rich ether group ( $-0-)$ in polymer backbone $\left(-\mathrm{CH}_{2}-\mathrm{CH}_{2}-\mathrm{O}-\right)$, desirable dielectric constant ( 4-5) and a broad range of salt complexation [17]. But the semi-crystalline nature of PEO results in lower ionic conductivity. It is well known that amorphous phase supports fast ion transport in case of polymer electrolytes [18]. The Sodium hexafluorophosphate $\left(\mathrm{NaPF}_{6}\right)$ was chosen as salt to provide ions due to advantages, (i) weak interaction between cation and anion, (ii) large anion size, and (iii) greater salt dissociation, hence reduce the chance of ion pair formation [19-21].

The incorporation of the Plastic crystals in the polymer matrix is an interesting approach for conductivity enhancement which is interpreted by assuming the effective role of plasticization effect. Succinonitrile $\left(\mathrm{SN} ; \mathrm{N} \equiv \mathrm{C}-\mathrm{CH}_{2}-\mathrm{CH}_{2}-\mathrm{C} \equiv \mathrm{N}\right)$ is a fascinating candidate as compared to the traditional plasticizer and is chosen due to high polarity, high dielectric constant $(\sim 55)$. The role of above-said characteristics property is interpreted in three ways, (i) the presence of polar nitrile group in SN will improve the salt dissociation and number of free charge carriers, (ii) SN penetration between polymer chain will provide more free volume for ion migration, (iii) disruption of covalent bonding between polymer chains will promote the faster chain segmental motion. The simultaneous presence of above properties will enable a favorable ion migration, and hence high ionic conductivity [22].

In our present study, free standing solid polymer electrolyte based on PEO as a host polymer, sodium hexafluorophosphate $\left(\mathrm{NaPF}_{6}\right)$ as salt, with different $\mathrm{SN}$ content are prepared by solution cast technique. The structural, morphological, microstructural and electrochemical investigations 
are carried out. Then the dielectric study covering the complex permittivity, complex conductivity, and the modulus formalism were explored in the frequency range $1 \mathrm{~Hz}-1 \mathrm{MHz}$. The dielectric plots were fitted to evaluate the dielectric strength, relaxation time, hopping time and the dc conductivity. Finally, we proposed an interesting interaction scheme to understand the role of constituents of solid polymer electrolytes in enhancing the ion transport.

\section{Methodology}

\section{Materials}

The polymer PEO (Av. Mol. Wt. 600,000 g/mol), sodium hexafluorophosphate $\left(\mathrm{NaPF}_{6}\right.$ ), Succinonitrile (SN) and Anhydrous acetonitrile were purchased from Sigma Aldrich. The polymer and salt are dried under vacuum at $50{ }^{\circ} \mathrm{C}$ for $24 \mathrm{~h}$ before use.

\section{Electrolyte preparation}

PEO-NaPF $6(\mathrm{O} / \mathrm{Na}=8)+x$ wt. $\% \mathrm{SN}$ polymer electrolytes were prepared by the standard solution cast technique. In this process, the appropriate amount of $\mathrm{PEO}$ and $\mathrm{NaPF}_{6}$ were dissolved separately to obtain the homogenous solution followed by stirring of combined solution until a homogenous and viscous solution is obtained. After that, the varying content of SN was added in the polymer salt complex and stirred again till a viscous solution is obtained. The obtained solution is poured into Petri dishes and left at room temperature to evaporate the solvent. After solvent evaporation, the films were kept in a vacuum oven to completely remove the solvent. Finally, the thin dry film was peeled off and kept in a vacuum desiccator for further investigations. The samples were designated as PE- $x$ where $x=1,2,3,4,5$. PE 1 designates the pure PEO and PE 2 designates the polymer salt complex (PEO-NaPF 6$), \mathrm{PE} 3$ to PE 5 is designated for the $x$ wt. $\%$ of SN added $(10,15,20 \%)$ in $\mathrm{PEO}-\mathrm{NaPF}_{6}$ sample. It may be noted that the further increase of $\mathrm{SN}$ content in polymer salt complex, results in poor quality of the films, hence not investigated.

\section{Characterization}

The Field emission scanning electron microscopy (FESEM) was used to investigate the surface morphology of prepared polymer electrolyte. The structural investigations were recorded by the $\mathrm{X}$-ray diffraction (XRD) (Bruker D8 Advance) with $\mathrm{Cu}-\mathrm{K}_{\alpha}$ radiation having a wavelength $(\lambda) 1.54$

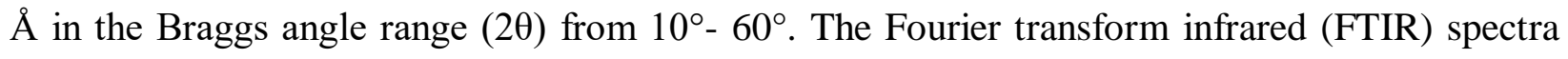
(Bruker Tensor 27) was performed in the wavenumber region $600-3500 \mathrm{~cm}^{-1}$ to confirm the various interactions between constituents of the polymer electrolyte. The ionic conductivity was measured by electrochemical impedance spectroscopy (EIS) using electrochemical analyzer (CHI 
760; USA) over a frequency range of $1 \mathrm{~Hz}$ to $1 \mathrm{MHz}$ and an AC signal of $10 \mathrm{mV}$ is was applied to the cell configuration $S S|S P E| S S$. The ion transference number was measured by i-t characteristics by applying a dc voltage of $10 \mathrm{mV}$. The electrochemical voltage stability window was measured by Linear sweep voltammetry technique (LSV) and cyclic voltammetry (CV) with cell configuration $S S|S P E| S S$. To investigate the dielectric properties the impedance data was transformed into the complex permittivity, complex conductivity which is further transformed into the real and imaginary part of the modulus.

\section{Results and Discussion}

\subsection{Field emission scanning electron microscope (FESEM) analysis}

The FESEM micrographs of the pure PEO (Figure 1 a) displays the rough morphology with some smoother surface due to semi-crystalline nature. Then the addition of salt alters the surface morphology significantly which is noticeable clearly from Figure $1 \mathrm{~b}$ and is comparatively smoother than Figure 1 a. This may be due to complexation of ether group of polymer host with the cation $\left(\mathrm{Na}^{+}\right)$of salt. After addition of SN in the polymer salt matrix the surface gets smoother $\&$ homogenous, also the incorporation of $\mathrm{SN}$ is uniform over the polymer matrix (Figure $1 \mathrm{c}$ ). This may be favorable for the fast ion migration which will be analyzed in the forthcoming section. The addition of very high SN content results in the insulating effect of SN due to improper mixing as visible in Figure 1d [23].
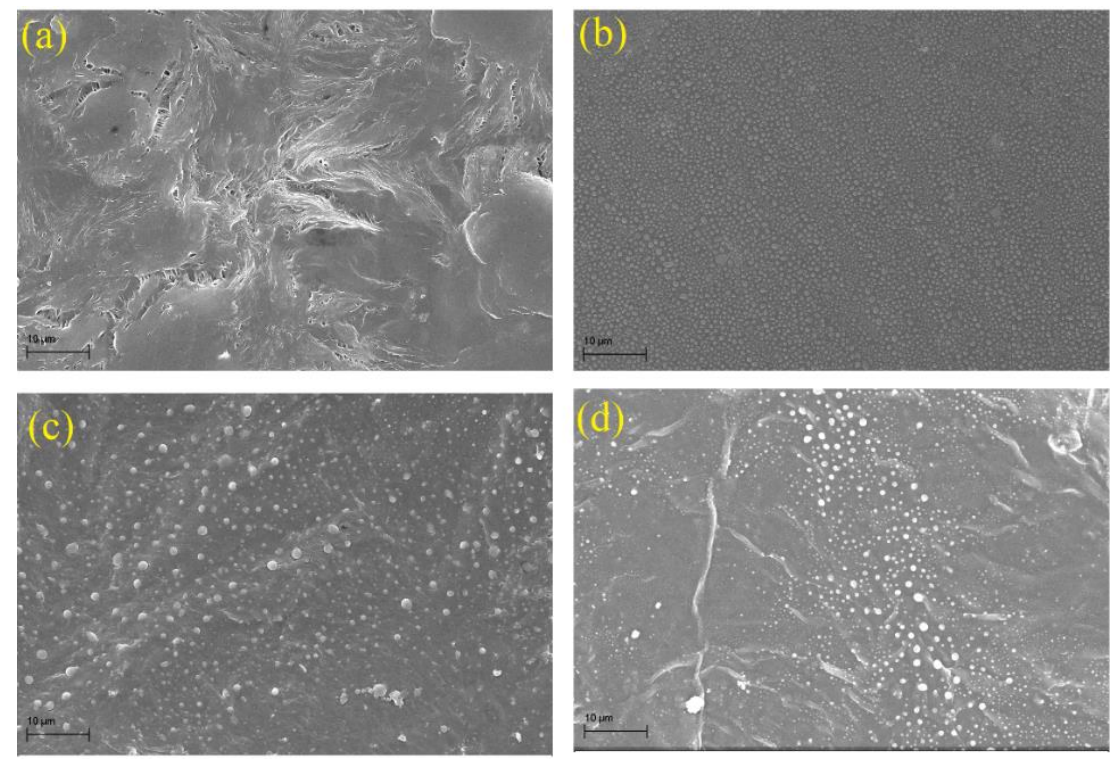

Figure 1. FESEM surface morphology of (a) PEO, (b) PEO-NaPF 6 , (c) PEO-NaPF $6-10 \% \mathrm{SN}$ and (d) PEO-NaPF $6-20 \%$ SN.

\subsection{X-ray diffraction (XRD) Analysis}


To examine the effect of SN addition on the crystallinity, interchain separation and inter-planer spacing, we performed the XRD analysis. Figure 2 shows the comparison of XRD diffractograms of the pure PEO, PEO-NaPF 6 , and PEO-NaPF $6^{-}$containing $x$ wt. \% SN $(x=10,15,20)$. It may be noticed from the diffraction pattern of pure PEO, two peaks are located at $19.03^{\circ}$ and $23.1^{\circ}$ corresponding to the (120) and (112/032) reflection planes. These peaks are primarily due to the crystalline nature of PEO and agree with the literature [24]. Figure * $b$ shows the reduction in peak intensity of PEO peaks that confirms the reduction in the crystallinity. It indicates the complex formation between the cation of salt and the ether group of the polymer host. This interaction enhances the amorphous content. Although with the addition of salt some additional peaks are observed that are not of pure $\mathrm{PEO} \& \mathrm{NaPF}_{6}$. The reason behind these peaks may be the presence of some sort of a long-range order set by the presence of ion-multiplets (as $\mathrm{Na}_{2} \mathrm{X}^{+}, \mathrm{NaX}_{2}^{-}$, etc.) [21, 25-26]. Further, the absence of any $\mathrm{NaPF}_{6}$ peak reveals the complete dissociation of salt and complex formation is confirmed [27-29].

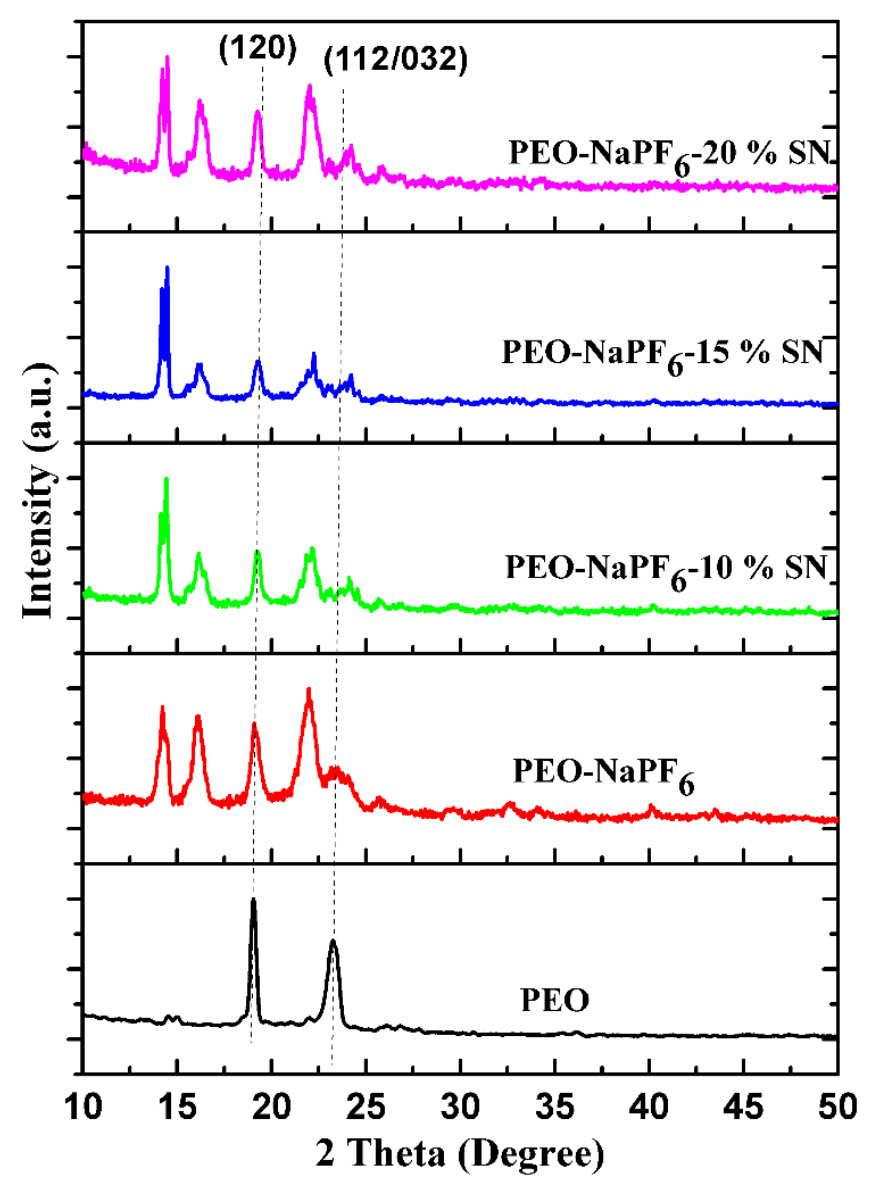

Figure 2. $\mathrm{XRD}$ patterns of the PEO, PEO-NaPF 6 , and PEO-NaPF $6^{-} x$ wt. \% SN $(\mathrm{x}=10,15,20)$. 
After addition of $\mathrm{SN}$ in the polymer salt matrix, the lowering in the intensity of PEO peak located at $19.03^{\circ}$ and $23.1^{\circ}$ evidence the effective role played by SN. The addition of SN having polar nitrile group in its structure promotes the salt dissociation and disruption of the crystalline arrangement of the PEO chains. The reduction of peak intensity clearly indicates the addition of $\mathrm{SN}$ enhances the amorphous content and promotes the faster segmental motion, hence the increase of ionic conductivity in the polymer matrix [30]. To support the above conclusion, the d-spacing was obtained using the Bragg's formula $2 d \sin \theta=\mathrm{n} \lambda$ and interchain separation (R) using the equation $\mathrm{R}=5 \lambda / 8 \sin \theta$. The lowering of the crystallinity suggests the increased free volume due to SN penetration between the polymers chain that weakens the covalent bonding between polymer chains. This was confirmed by the Table 1, which shows the increase in the interchain separation (R) for all polymer electrolyte with $\mathrm{SN}$ addition and comparatively large $\mathrm{R}$ is noticed than pure PEO and polymer salt complex.

Table 1. Values of $2 \theta$ (degree), d-spacing $(\AA)$ and R $(\AA)$ of PEO-NaPF 6 with $x$ wt. \% SN (10, 15, 20).

\begin{tabular}{|c|c|c|c|}
\hline \multirow[t]{2}{*}{ Sample } & \multicolumn{3}{|c|}{ (120) diffraction peak } \\
\hline & $2 \theta$ (degree) & d-spacing $(\AA)$ & $\mathbf{R}(\mathbf{A})$ \\
\hline PE 1 & 19.03 & 4.66 & 5.82 \\
\hline PE 2 & 18.87 & 4.69 & 5.87 \\
\hline PE 3 & 18.73 & 4.73 & 5.91 \\
\hline PE 4 & 18.58 & 4.76 & 5.94 \\
\hline PE 5 & 18.36 & 4.82 & 6.02 \\
\hline
\end{tabular}

\subsection{Fourier transform infrared (FTIR) Spectrum Analysis}

The interactions of salt and SN with the polymer host are investigated by the FTIR spectra. The FTIR absorbance spectra of the pure polymer and polymer salt complex with $x$ wt. $\%(x=0,10,15$, 20) SN are shown in Figure 3 and band assignment is summarized in Table 2. It is found that the pure PEO spectrum shows the $\mathrm{C}-\mathrm{O}$ stretching vibration mode at $956 \mathrm{~cm}^{-1}$. The fundamental peak of the PEO is C-O-C stretching mode located at $1106 \mathrm{~cm}^{-1}$. The $\mathrm{CH}_{2}$ symmetric twisting, $\mathrm{CH}_{2}$ asymmetric twisting, $\mathrm{CH}_{2}$ bending mode, $\mathrm{CH}_{2}$ wagging mode are observed at $1236 \mathrm{~cm}^{-1}, 1282 \mathrm{~cm}^{-}$ $1,1347 \mathrm{~cm}^{-1}, 1465 \mathrm{~cm}^{-1}$ respectively [31]. It may be noted from the FTIR spectrum that all the groups of PEO, salt and SN are present it indicates the complex formation of PEO, NaPF6, and $\mathrm{SN}$. After the addition of the salt, the $\mathrm{CH}_{2}$ twisting and $\mathrm{CH}_{2}$ bending group show modification in the peak shape and shift in peak position. The band located at $1465 \mathrm{~cm}^{-1}$ is ascribed to $\mathrm{CH}_{2}$ wagging mode and displays reduction of peak intensity with the addition of the salt. The peaks in the wavenumber region $2800 \mathrm{~cm}^{-1}$ to $2950 \mathrm{~cm}^{-1}$ are ascribed to the symmetric and asymmetric 
vibration of $\mathrm{C}-\mathrm{H}$ stretching mode of $\mathrm{CH}_{2}$ group in $\mathrm{PEO}$. The spectrum shows the change in peak intensity that evidences the polymer-salt interaction [32-33]. Further addition of SN alters the peak shape as well as position and indicates the complexation between the constituents of solid polymer electrolytes. Although the characteristics peak still remains in the spectrum but some alteration is noticed. The peak of C-O-C stretching mode located at $1106 \mathrm{~cm}^{-1}$ is strongly affected after SN addition and get broadened with addition of SN, also peak intensity get reduced. The obtained reduction in the peak intensity is attributed to the cation $\left(\mathrm{Na}^{+}\right)$coordination with the lone pair of electrons (ether group) on PEO [34]. So, from the FTIR analysis, it can be concluded that the complexation of the salt and polymer occurs and the result is in absolute agreement with the XRD and FESEM results.

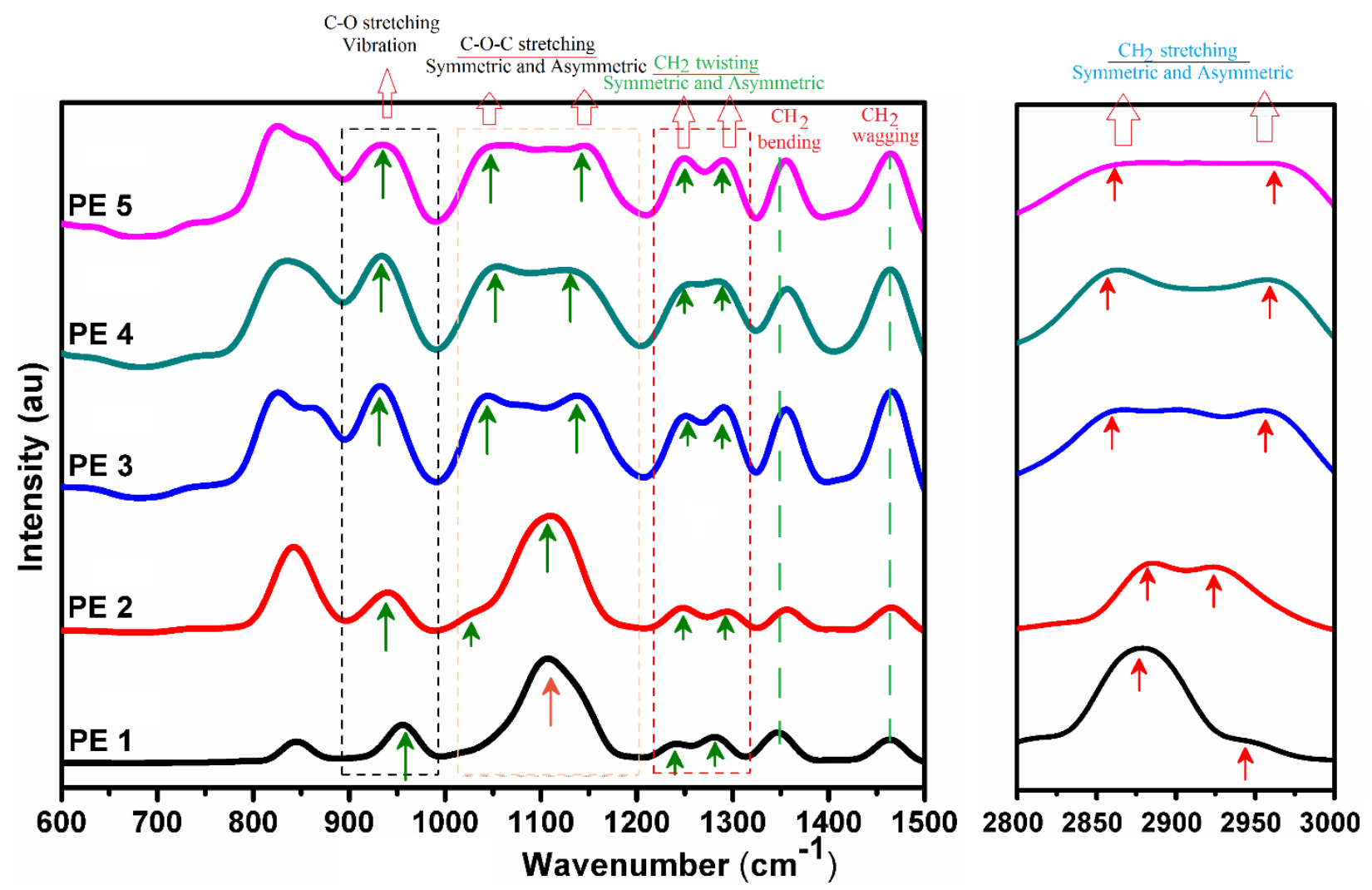

Figure 3. FTIR spectra of pure PEO (PE 1), polymer salt (PE 2), and with $x$ wt. \% of SN ( $x=10$, $15,20)$ (PE 3 to PE 5).

Table 2. FTIR spectral data of PEO, $\mathrm{PEO}-\mathrm{NaPF}_{6}$, and $\mathrm{SN}$ added $\mathrm{PEO}-\mathrm{NaPF}_{6}$ based solid polymer electrolyte.

\begin{tabular}{|c|c|c|c|c|c|}
\hline \multicolumn{5}{|c|}{ Wavenumber $\left(\mathbf{c m}^{-1}\right)$} & Band Assignment \\
\hline PE 1 & PE 2 & PE 3 & PE 4 & PE 5 & \\
\hline 845 & 842 & 827 & 831 & 824 & C-O stretching in PEO and F $_{6}^{-}$vibration \\
\hline 956 & 938 & 933 & 933 & 935 & C-O stretching vibration \\
\hline 1106 & 1107 & $1044 / 1139$ & $1050 / 1134$ & $1047 / 1143$ & Symmetric and asymmetric C-O-C stretching \\
\hline
\end{tabular}




\begin{tabular}{|c|c|c|c|c|c|}
\hline 1236 & 1246 & 1251 & 1251 & 1249 & $\mathrm{CH}_{2}$ symmetric twisting \\
\hline 1282 & 1294 & 1291 & 1287 & 1292 & Asymmetric $\mathrm{CH}_{2}$ twisting \\
\hline 1347 & 1356 & 1354 & 1354 & 1354 & $\mathrm{CH}_{2}$ bending \\
\hline 1465 & 1465 & 1467 & 1464 & 1464 & $\mathrm{CH}_{2}$ wagging \\
\hline 2877 & 2882 & 2864 & 2858 & 2858 & Symmetric C-H stretching \\
\hline 2948 & 2922 & 2956 & 2960 & 2962 & Asymmetric C-H stretching \\
\hline
\end{tabular}

\subsection{Impedance Study}

The ionic conductivity of the solid polymer electrolytes (SPE) was investigated at room temperature by applying a signal of $\sim 10 \mathrm{mV}$ across the cell configuration SS|SPE|SS and the impedance plot ( $Z^{\prime \prime}$ vs. $\left.Z^{\prime}\right)$ is shown in Figure 4 in the log-log presentation. The advantage of log$\log$ representation is summarized somewhere [21]. It may be noted that the impedance plot shows two arcs, (i) towards lower frequency, and (ii) toward high frequency [35-36]. The arc at highfrequency side confirms the active ion migration in the polymer matrix while the arc toward the right side of the graph (lower frequency side) may be attributed to the double layer capacitance effect formed at the electrode-electrolyte interface due to ion blockage [37-40]. With the addition of $\mathrm{SN}$, the high-frequency arc is disappeared and indicates that total conductivity is owing to the cation only $(\sigma=n e \mu)$. The same feature has been reported earlier also [41-42]. Although nature of the plot is same for all solid polymer electrolytes with some change in the arc shape.

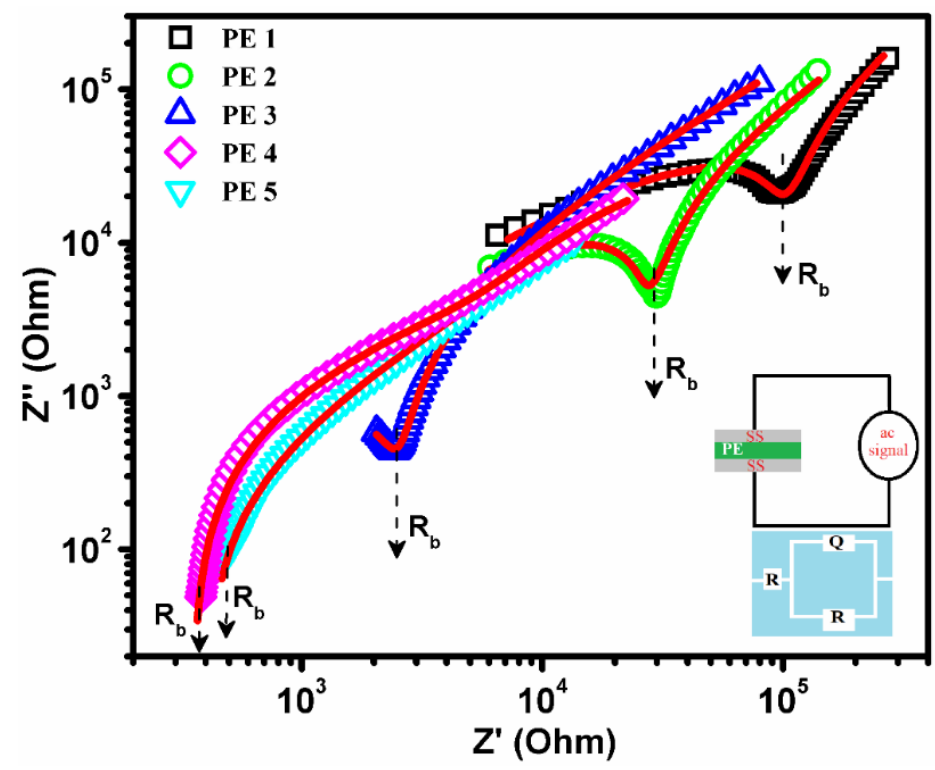

Figure 4. Log-log plots of the complex impedance $\left(Z^{\prime \prime} v s . Z^{\prime}\right)$ for the pure PEO (PE 1), polymer salt complex (PE 2) and $x$ wt. \% SN (x=10, 15, 20); (PE3, PE 4, PE 5).

The ionic conductivity $(\sigma)$ of the prepared polymer electrolyte has been determined using the equation: 


$$
\sigma=\frac{L}{R_{b} \times S}
$$

were, ' $L$ ' is the thickness of the polymer electrolyte $(100-125 \mu \mathrm{m})$, ' $\mathrm{S}$ ' is the area of the blocking electrode $\left(1.43 \mathrm{~cm}^{2}\right)$ and $\mathrm{R}_{\mathrm{b}}$ is the bulk resistance of polymer electrolyte films.

The dip observed in the impedance plot (corresponds to minima in $\mathrm{Z}^{\prime \prime}$ ) gives the bulk resistance. On addition of salt and SN, the bulk resistance decreases. As bulk resistance is inversely proportional to conductivity value, so decrease in the bulk resistance indicates the increase in the conductivity of prepared SPE. Therefore, the enhancement in the ionic conductivity is due to the following reasons, (i) availability of more number of ion charge carriers due to better salt dissociation after SN addition, (ii) faster ion mobility and (iii) increase in the free volume and amorphous phase for the ion migration. It may be concluded from the above results that the addition of $\mathrm{SN}$ in the polymer salt complex promotes the migration of the cation with polymer chain segmental motion.

The polymer electrolyte system PE4 is optimized sample and exhibits the highest conductivity $1.92 \times 10^{-5} \mathrm{~S} \mathrm{~cm}^{-1}$, which is three orders higher than the pure polymer, two orders higher than the polymer salt complex. The fitted equivalent circuit comprises a resistance in series with the parallel combination of constant phase element and another resistance. Also, the experimental and fitted data are in good agreement with each other. Further, the double layer capacitance is calculated using the equation 2 and given in table 3:

$$
C_{d l}=\frac{1}{-\omega Z^{\prime \prime}}
$$

Where $\omega$ is he angular frequency and $Z^{\prime \prime}$ is the imaginary part of impedance at low frequency. It is interesting to note that the SPE system with the highest value of the ionic conductivity possess the highest double layer capacitance $\left(C_{d l}\right)$. The increase in the conductivity is further investigated in terms of dielectric properties in the forthcoming section.

\subsection{Transference Number}

In case of solid polymer electrolytes, both ions and electrons are active species. So, to completely understand the enhancement of the ionic conductivity it is important to separate out the ionic and electronic contribution [43-44]. Ionic transference number was measured by Wagner's DC polarization technique at a fixed applied voltage $(20 \mathrm{mV})$ across the cell SS/SPE polymer electrolyte/SS (@ RT). The variation of polarization current is plotted against the time for the 
polymer salt complex (PE 2) and SN incorporated polymer electrolytes (PE 3, PE 4, PE 5::10, 15, 20 wt. \% SN) at room temperature is shown in Figure 5. It is observed that for all SPEs, the initial current decreases with time and achieved steady state in small time. The initial current is the contribution of both the ions and the electrons $\left(I_{t}=I_{e}+I_{i}\right)$ while the later one is the contribution of electrons only because of blockage of ions at the electrode-electrolyte interface [45-47]. The obtained ion transference number is 0.99 (close to unity). This infers that the total ionic conductivity is mainly due to the flow of ions and electron contribution to total conductivity is negligible, which is desirable for the solid state ionic conductor (Table 3). Also, the transference number clos to unity eliminates the issue of concentration polarization during cell operation [48]. Table 3. Different contributions of electrical, electronic, ionic conductivity, transference number and voltage stability window of SPE.

\begin{tabular}{|c|c|c|c|c|c|}
\hline $\begin{array}{c}\text { Sample } \\
\text { Code }\end{array}$ & $\begin{array}{c}\text { Transference } \\
\text { Number }\end{array}$ & $\begin{array}{c}\text { Electrical } \\
\text { Conductivity } \\
\left(\mathbf{S ~ c m}^{-\mathbf{1}}\right)\end{array}$ & $\begin{array}{c}\text { Electronic } \\
\text { Conductivity } \\
\left(\mathbf{S ~ c m ~}^{-1}\right)\end{array}$ & $\begin{array}{c}\text { Ionic } \\
\text { Conductivity } \\
\left(\mathbf{S ~ c m}^{-1}\right)\end{array}$ & $\begin{array}{c}\text { Voltage } \\
\text { stability } \\
\text { Window (V) }\end{array}$ \\
\hline PE 1 & - & $4.95 \times 10^{-8}$ & - & - & - \\
\hline PE 2 & 0.98 & $1.95 \times 10^{-7}$ & $3.90 \times 10^{-9}$ & $1.91 \times 10^{-7}$ & 3.37 \\
\hline PE 3 & 0.97 & $2.80 \times 10^{-6}$ & $8.40 \times 10^{-8}$ & $2.71 \times 10^{-6}$ & 3.92 \\
\hline PE 4 & 0.98 & $1.92 \times 10^{-5}$ & $3.84 \times 10^{-7}$ & $1.88 \times 10^{-5}$ & 3.79 \\
\hline PE 5 & 0.99 & $1.44 \times 10^{-5}$ & $1.44 \times 10^{-7}$ & $1.42 \times 10^{-5}$ & 3.40 \\
\hline
\end{tabular}

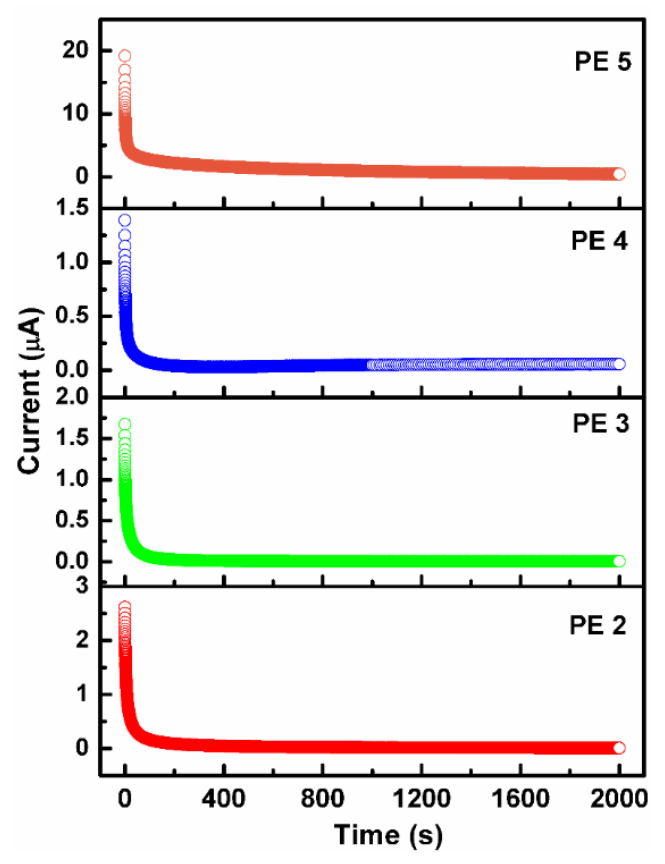

Figure 5. Ion transference number plots for the prepared solid polymer electrolytes at room temperature. 
The ionic and electronic conductivity are also calculated through suitable equations 3 as given in in table 3 .

$$
\left\{\begin{array}{c}
\mathrm{i}_{\mathrm{t}}=\mathrm{i}_{\mathrm{i}}+\mathrm{i}_{\mathrm{e}} \\
\sigma_{\text {ionic }}=\sigma_{\text {electrical }} \times \mathrm{i}_{\mathrm{i}} \\
\sigma_{\text {electronic }}=\sigma_{\text {electrical }} \times i_{\mathrm{e}}
\end{array}\right.
$$

The high value of ionic conductivity and negligible electronic conductivity evidence that the charge transport in the investigated system is due to ions only.

\subsection{Electrochemical Stability Window}

The electrochemical voltage stability window or working voltage range of SPE has been measured by linear sweep voltammetry (LSV) \& cyclic voltammetry (CV) technique which is sandwiched in cell assembly SS (blocking electrodes)/SPE polymer electrolyte/ SS (blocking electrodes) at RT (Scan rate $10 \mathrm{mV} / \mathrm{s}$ ) ${ }^{[49]}$. The LSV and the CV curves are shown in Figure 6 and Figure 7 , respectively. Figure 6 shows the steady current up to $3 \mathrm{~V}$ and after that rapid increase in the current flows which is due to the electrolyte decomposition ${ }^{[50] . ~ T h e ~ v o l t a g e ~ s t a b i l i t y ~ w i n d o w ~ o f ~ t h e ~ S P E ~}$ containing SN displays improved stability (3.5 V-3.9 V) as compared to polymer salt system (3.3 V). It suggests that there is no decomposition of the lectrolyte at least up to this range ( $4 \mathrm{~V})$. The enhancement in the voltage stability window suggests the use of SPE in the high voltage practical applications within a safe limit.

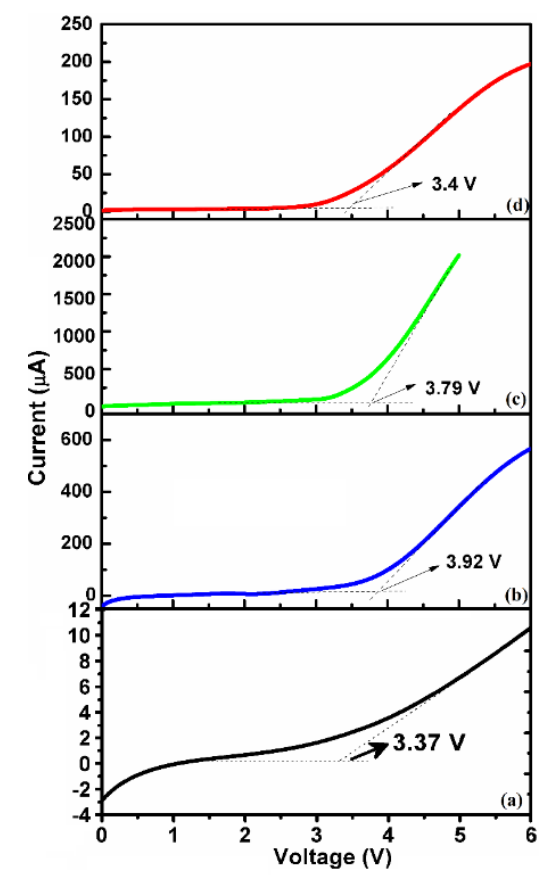


Figure 6. Linear sweep voltammetry for the (a) PE 2, (b) PE 3, (c) PE 4 and (d) PE 5 in the configuration SS $\|$ SPE $\|$ SS

The enhancement in the electrochemical stability window (ESW) is further supported by the cyclic voltammogram (Figure 7). The ESW is the region where no faradic current flows and is evaluated by cathodic/anodic component where oxidation/reduction of solid polymer electrolytes is observed [51]. The absence of any oxidation-reduction peak in CV confirms the better electrochemical stability of the prepared solid polymer electrolyte. The solid polymer electrolyte with highest ionic conductivity shows ESW in the range $-2 \mathrm{~V}$ and $2.1 \mathrm{~V}$. This gives ESW of about $4.1 \mathrm{~V}$. It may be noted that after SN addition broadening in ESW is evidenced and all solid polymer electrolyte shows ESW of about $\sim 4 \mathrm{~V}$. From the results, it may be concluded that the prepared SPE possess desirable voltage stability window for the practical applications.

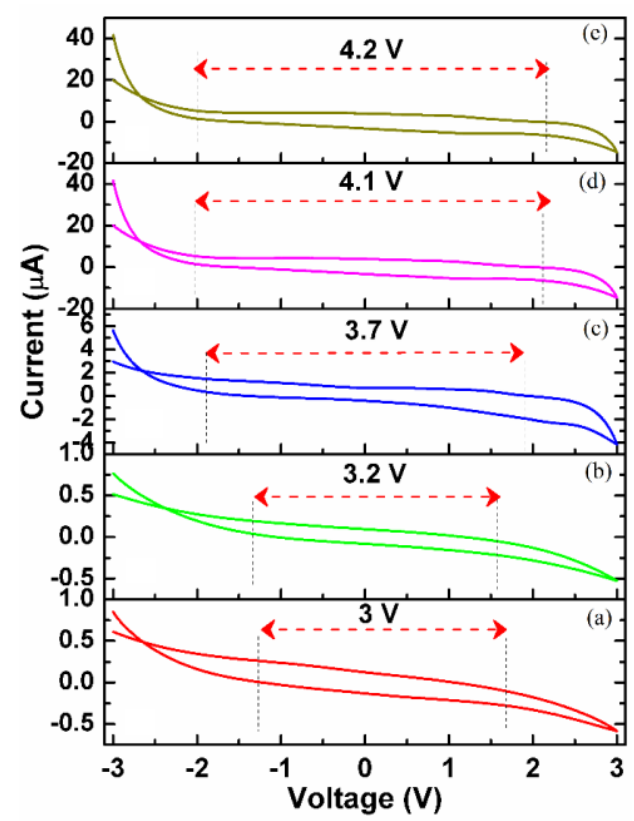

Figure 7. Cyclic voltammetry of the (a) PE 1, (b) PE 2, (c) PE 3, (d) PE 4 and (e) PE 5 in the configuration SS/SPE/SS.

\subsection{Dielectric analysis}

\subsubsection{Real $\left(\varepsilon^{\prime}\right)$ and imaginary $\left(\varepsilon^{\prime \prime}\right)$ part of complex permittivity $\left(\varepsilon^{*}\right)$}

The complex permittivity $\left(\varepsilon^{*}\right)$ investigations of solid polymer electrolyte are crucial to understanding the polarization effect at the electrode-electrolyte interface [52-54]. The frequency dependent complex dielectric permittivity comprises of two parts, real part $\left(\varepsilon^{\prime}\right)$ designates polymer electrolyte polarizing ability that indicates charge storage capacity or storage capacity of a material 
on application of field. The imaginary part i.e. dielectric loss $\left(\varepsilon^{\prime \prime}\right)$ is a measure of the energy required to align the dipoles and is expressed by equation 4 ;

$$
\varepsilon^{*}=\varepsilon^{\prime}-j \varepsilon^{\prime \prime} ; \varepsilon^{\prime}=\frac{-Z^{\prime \prime}}{\omega C_{o}\left(Z^{\prime 2}+Z^{\prime 2}\right)} \text { and } \varepsilon^{\prime \prime}=\frac{Z^{\prime}}{\omega C_{o}\left(Z^{\prime 2}+Z^{\prime 2}\right)}
$$

The real and imaginary parts are written from the Debye equation [55] and expressed as;

$$
\begin{gathered}
\varepsilon^{\prime}=\epsilon_{\infty}+\frac{\Delta \varepsilon\left(1+x^{\alpha} \cos \frac{\alpha \pi}{2}\right)}{1+2 x^{\alpha} \cos \frac{\alpha \pi}{2}+x^{2 \alpha}} \\
\varepsilon^{\prime \prime}=\Delta \varepsilon \frac{x^{\alpha} \sin \frac{\alpha \pi}{2}}{1+2 x^{\alpha} \cos \frac{\alpha \pi}{2}+x^{2 \alpha}}
\end{gathered}
$$

Here, $\varepsilon_{s}$ is static dielectric constant $(x \rightarrow 0), \varepsilon_{\infty}$ is dielectric constant $(x \rightarrow \infty), x=\omega \tau$; $\omega$ is the angular frequency, $\tau$ is relaxation time and $\alpha$ is power law exponent. All these parameters are evaluated by fitting the experimental data with these equations and are summarized in Table 4.

The variation of dielectric constant $\left(\varepsilon^{\prime}\right)$ against frequency for different solid polymer electrolyte is shown in Figure 9 and solid red line is fit to experimental data. All the SPE shows good agreement between the experimental and fitted curve.

In Figure 9 it may be noticed that at low-frequency rapid increase in $\varepsilon^{\prime}$ is observed attributed to the accumulation of the charge at the electrode/electrolyte interface [56]. While at the high frequency, a decrease in dielectric constant is observed with the increase of frequency. This may be due to the blockage of ion diffusion or migration because of fast periodic reversal of the electric field. Now, the dipoles are unable to orient themselves in the applied filed direction. This eliminates the electrode polarization and dominance of relaxation mechanism occurs, which leads to steady state at high frequency [27, 57-60].

In case of solid polymer electrolytes two sources of dipoles exist, (i) salt dissociation produce cation-anion, and (ii) polar groups of the polymer chain. The increased charge accumulation on the blocking electrodes in the low-frequency window is mainly due to cation/anion migration (first source) toward electrodes on the application of the field. The second source of dipoles in the polar group of polymer chain makes conformational changes [61]. So, both phenomena together result in the enhancement in the dielectric constant of about $\sim 10^{4}$ and are comparatively higher dielectric constant is observed for SN based SPE $\left(\sim 30 \times 10^{4}\right)$ as compared to polymer salts system $\left(\sim 4 \times 10^{4}\right)$. Now, after addition of salt in the pure PEO, dielectric constant increases due to the enhancement of the amorphous content. Further addition of SN in the polymer salt matrix increases the dielectric 
constant. This is evidenced from the Table 4, which shows increase dielectric strength $\left(\Delta \varepsilon=\varepsilon_{s}-\right.$ $\varepsilon_{\infty}$ ) after $\mathrm{SN}$ addition. This may be due to two reasons, (i) disruption of the crystalline arrangement of host polymer chains, (ii) enhancement of amorphous content and (iii) decrease of viscosity of polymer chain due to disruption of covalent bonding between polymer chains after SN penetration. The increase of the dielectric strength reflects the increase in the number of the charge carriers. Also, the solid polymer electrolyte having highest ionic conductivity possess highest dielectric strength. This suggests that the increase in the ionic conductivity is due to increase in number of charge carriers [62]. This evidences the correlation between the dielectric constant and the ionic conductivity. Another important parameter is the relaxation time. The low value of relaxation time results in the faster ion migration via chain segmental motion. The relaxation time $\left(\boldsymbol{\tau}_{\boldsymbol{\varepsilon}^{\prime}}\right)$ was extracted from the fitting of experimental data, and the optimized sample shows the lowest value of relaxation time [63-64]. Another relaxation time i.e. molecular relaxation time $\left(\tau_{M}\right)$ was obtained using the equation $6[65]$;

$$
\tau_{M}=\left[\frac{\left(2 \varepsilon_{s}+\varepsilon_{\infty}\right)}{3 \varepsilon_{s}}\right] \times \tau_{\varepsilon^{\prime}}
$$

It is interesting to note that, the molecular relaxation time is also lowest for the optimized system and is in proper agreement with the relaxation time $\left(\boldsymbol{\tau}_{\varepsilon^{\prime}}\right)$, dielectric strength $(\Delta \varepsilon)$ and ionic conductivity.

Table 4. Various parameters obtained from fitting of $\varepsilon^{\prime}\left(\varepsilon_{\infty}, \Delta \varepsilon, \tau_{\varepsilon^{\prime}}, \alpha\right)$ and $\boldsymbol{\varepsilon}^{\prime \prime}\left(\Delta \varepsilon, \tau_{\varepsilon}^{\prime \prime}, \alpha\right)$ plot at room temperature.

\begin{tabular}{|c|c|c|c|c|c|c|c|c|}
\hline \multirow{2}{*}{ Sample Code } & \multicolumn{9}{|c|}{$\boldsymbol{\varepsilon}^{\prime}$} & \multicolumn{3}{|c|}{$\boldsymbol{\varepsilon}^{\prime \prime}$} \\
\cline { 2 - 9 } & $\boldsymbol{\varepsilon}_{\infty}$ & $\boldsymbol{\Delta} \boldsymbol{\varepsilon}\left(\times \mathbf{1 0}^{\mathbf{3}}\right)$ & $\boldsymbol{\tau}_{\boldsymbol{\varepsilon}^{\prime}}(\boldsymbol{\mu \mathbf { s } )}$ & $\boldsymbol{\tau}_{\mathbf{M}}(\boldsymbol{\mu \mathbf { s }})$ & $\boldsymbol{\alpha}$ & $\boldsymbol{\Delta} \boldsymbol{\varepsilon}\left(\times \mathbf{1 0}^{\mathbf{3}}\right)$ & $\boldsymbol{\tau}_{\boldsymbol{\varepsilon}^{\prime \prime}}(\boldsymbol{\mu \mathbf { s }})$ & $\boldsymbol{\alpha}$ \\
\hline PE 1 & 20 & 10.27 & 1.69 & 1.12 & 0.83 & 19.93 & 1.82 & 0.78 \\
\hline PE 2 & 189 & 91.16 & 0.57 & 0.37 & 0.64 & 401.70 & 1.08 & 0.63 \\
\hline PE 3 & 1152 & 124.47 & 0.20 & 0.13 & 0.48 & 430.74 & 0.87 & 0.42 \\
\hline PE 4 & 1865 & 940.54 & 0.09 & 0.05 & 0.53 & 3998.57 & 0.26 & 0.52 \\
\hline PE 5 & 75 & 116.82 & 0.61 & 0.40 & 0.52 & 3356.01 & 0.52 & 0.56 \\
\hline
\end{tabular}



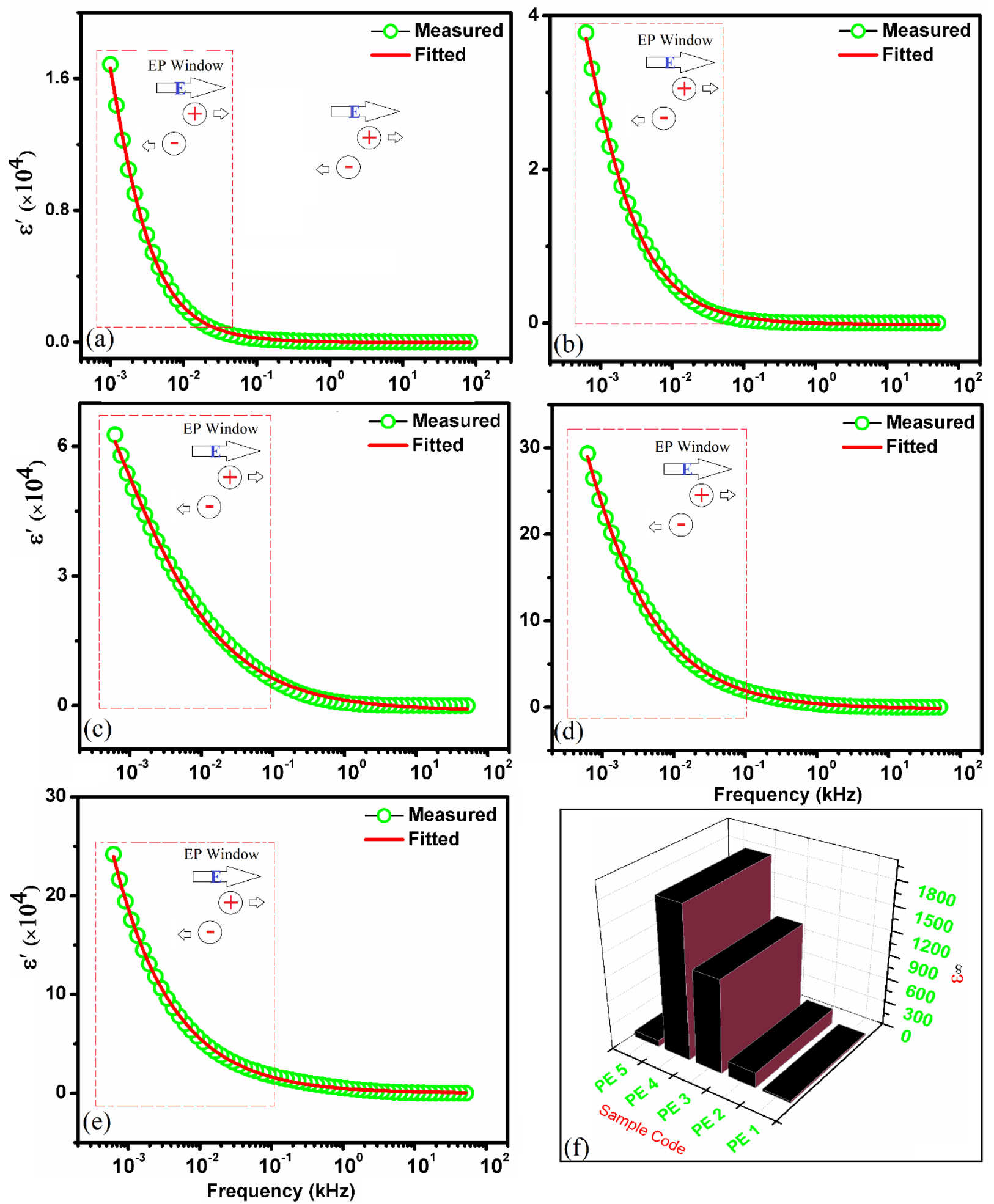

Figure 9. Frequency dependence of the dielectric constant $\left(\boldsymbol{\varepsilon}^{\prime}\right)$ for the (a) PEO, polymer salt $+x$ wt. $\%$ SN (b) 0, (c) 10, (d) 15, (e) 20, and (f) variation of $\varepsilon_{\infty}$ with for various SPE. Solid lines are the best fit to the experimental data (a-e). 

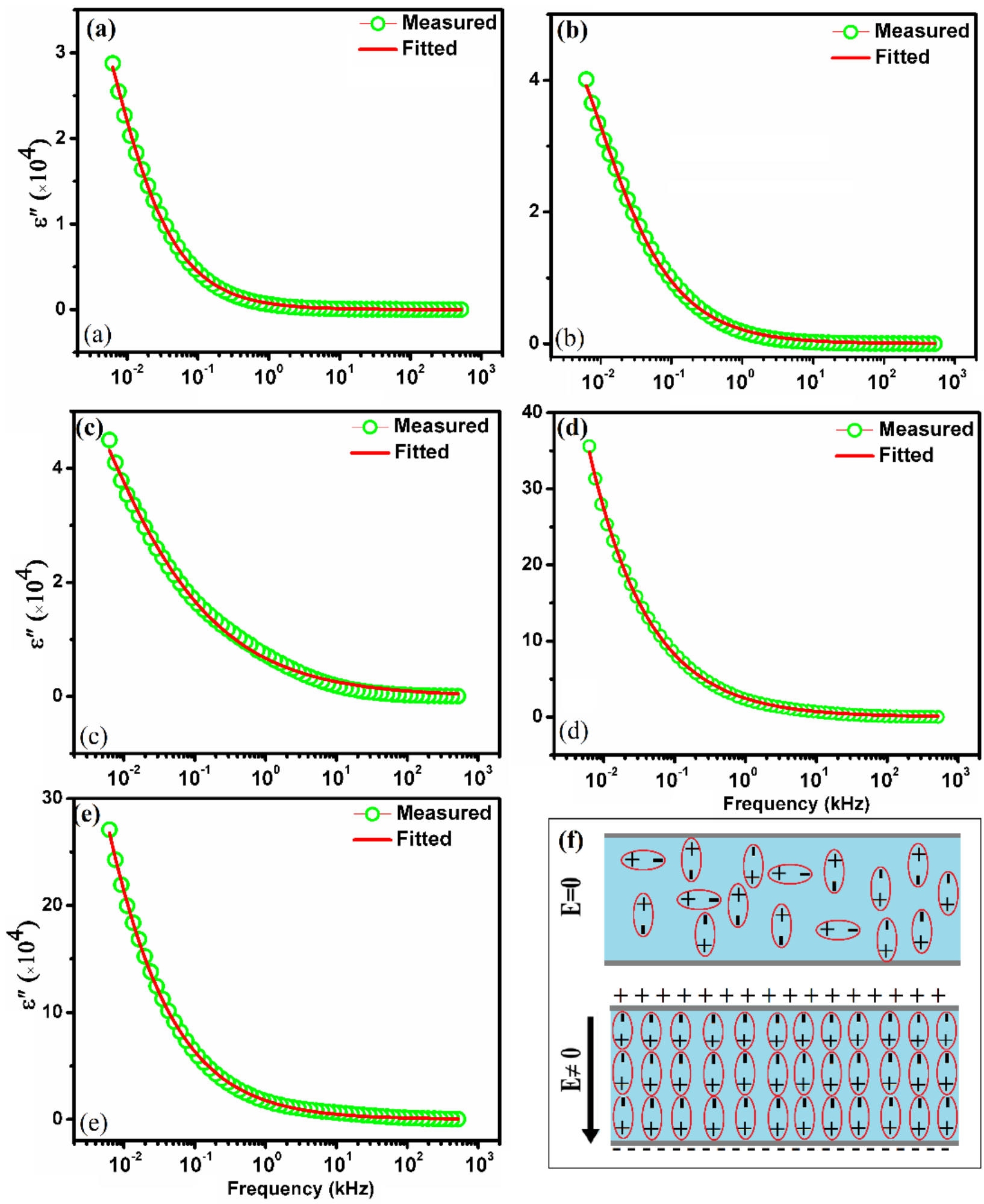

Figure 10. Frequency dependence of the dielectric constant $\left(\boldsymbol{\varepsilon}^{\prime \prime}\right)$ for the (a) PEO, polymer salt $+x$ wt. \% SN (b) 0, (c) 10, (d) 15, (e) 20, and f. polarization mechanism. Solid lines are the best fit to the experimental data (a-e). 
The frequency dependent imaginary part of the dielectric permittivity or dielectric loss $\left(\varepsilon^{\prime \prime}\right)$ is shown in Figure 10. It is observed that the dielectric loss $\left(\varepsilon^{\prime \prime}\right)$ value decreases with the increase of frequency for all solid polymer electrolytes [66]. The experimental data are in good agreement to the fitted data shown by a red solid line. As at high frequency, periodic reversal of field occurs that generates internal heat due to friction. Besides this, the dipoles are insufficient to orient along field direction and contribute to dielectric loss dielectric loss [67-68.]. This dielectric loss increases with increase in a number of charge carriers as evidenced from the Figure 10 and becomes frequency independent at high frequency. The decrease in both dielectric constant $\left(\varepsilon^{\prime}\right)$ and dielectric loss $\left(\varepsilon^{\prime \prime}\right)$ reflects the Non-Debye behavior shown by present solid polymer electrolyte system [69].

\subsubsection{Sigma ( $\sigma^{\prime \prime}$ vs. $\left.\sigma^{\prime}\right)$ Representation}

The sigma representation is crucial for getting an insight of the dispersion region at a high frequency in the Cole-Cole plot and is the plot of imaginary part $\left(\sigma^{\prime \prime}\right)$ vs. real part $\left(\sigma^{\prime}\right)$ conductivity [70]. The complex conductivity is expressed using equation 7;

$$
\left\{\begin{array}{c}
\sigma(\omega)=\sigma^{\prime}+i \sigma^{\prime \prime} \\
\sigma_{\infty}=\sigma_{o}+\frac{\varepsilon_{v}\left(\varepsilon_{0}-\varepsilon_{\infty}\right)}{\tau}=\sigma_{o}+\delta \\
\sigma_{a c}=\sigma^{\prime}=\omega \varepsilon_{v} \varepsilon^{\prime \prime} \text { and } \sigma_{d c}=\sigma^{\prime \prime}=\omega \varepsilon_{v}\left(\varepsilon^{\prime}-\varepsilon_{\infty}\right)=\omega \varepsilon_{v} \varepsilon^{\prime} \\
r=\frac{\delta}{2}=\frac{\varepsilon_{v}\left(\varepsilon_{o}-\varepsilon_{\infty}\right)}{2 \tau}
\end{array}\right.
$$

Where, $\sigma^{\prime}, \sigma^{\prime \prime}, \omega, r$ are the real part of conductivity, imaginary part of conductivity, angular frequency and radius of the semi-circle. The dc conductivity $\left(\sigma_{o}\right)$ value is extracted from the minima at low frequency x-intercept $\left(\sigma^{\prime \prime}=0\right)$ and high frequency x-intercept enables to obtain $\sigma_{\infty}$ (Figure $11 \mathrm{a}-\mathrm{e}$ ). In the sigma representation, the radius of the micircle (r) is inversely proportional to the relaxation time $(\tau)$. Table 5 summarizes the various parameters obtained from the plot. It is apparent from the Table and Figure 11 that the diameter of the semi-circle increases with addition of SN in the polymer salt complex. This implies the decrease of relaxation time $(r \propto 1 / \tau)$. As $r$ value is highest for the PE 4 system which exhibits the highest ionic conductivity also. It suggests that Sigma representation provides sufficient evidence of the faster ion migration for PE 4 system and decrease in relaxation time follows the trend of relaxation time $\left(\tau_{\varepsilon^{\prime}}\right)$ and molecular relaxation time $\left(\tau_{M}\right)$. 

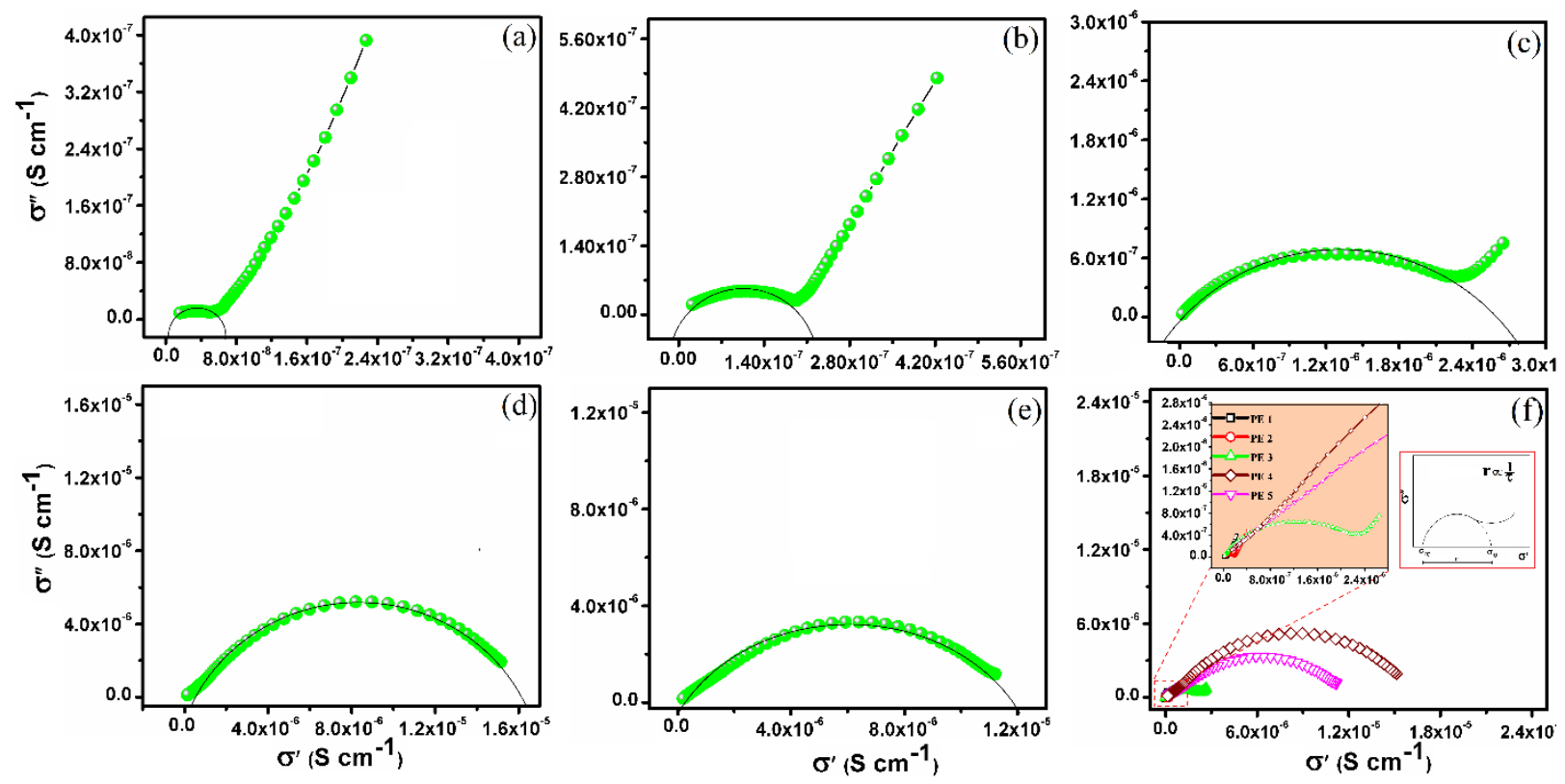

Figure 11. Sigma Representation ( $\left.\sigma^{\prime \prime} v s . \sigma^{\prime}\right)$ of the (a) PE 1, (b) PE 2, (c) PE 3, (d) PE 4, (e) PE 5 and (f) comparative plot of all solid polymer electrolyte.

Table 5. The measured parameter, $\sigma_{o}, \sigma_{\infty}, \delta$ and $r$ from the plot of $\sigma^{\prime \prime} v s . \sigma^{\prime}$ for various SPEs at RT.

\begin{tabular}{|c|c|c|c|c|}
\hline Sample Code & $\boldsymbol{\sigma}_{\boldsymbol{o}}\left(\mathrm{S} \mathrm{cm}^{-1}\right)$ & $\boldsymbol{\sigma}_{\infty}\left(\mathrm{S} \mathrm{cm}^{-1}\right)$ & $\boldsymbol{\delta}\left(\times \mathbf{1 0}^{-7}\right)$ & $\boldsymbol{r}\left(\times \mathbf{1 0}^{-7}\right)$ \\
\hline PE 1 & $6.12 \times 10^{-9}$ & $7.03 \times 10^{-8}$ & 0.64 & 0.32 \\
\hline PE 2 & $1.59 \times 10^{-8}$ & $2.01 \times 10^{-7}$ & 1.85 & 0.92 \\
\hline PE 3 & $1.27 \times 10^{-7}$ & $2.75 \times 10^{-6}$ & 26.23 & 13.11 \\
\hline PE 4 & $0.63 \times 10^{-6}$ & $1.62 \times 10^{-5}$ & 155.82 & 77.91 \\
\hline PE 5 & $0.13 \times 10^{-6}$ & $1.21 \times 10^{-5}$ & 119.71 & 59.85 \\
\hline
\end{tabular}

\subsubsection{The real part of the complex conductivity}

The complex conductivity of the solid polymer electrolytes is expressed by equation 8 ,

$$
\sigma^{*}(\omega)=\sigma^{\prime}(\omega)+i \sigma^{\prime \prime}(\omega)
$$

The real part is expressed as $\sigma^{\prime}=\sigma_{a c}=\omega \varepsilon_{o} \varepsilon^{\prime \prime}=\omega \varepsilon_{o} \varepsilon^{\prime} \tan \delta$, and imaginary part as $\sigma^{\prime \prime}=\omega \varepsilon_{o} \varepsilon^{\prime}=$ $\omega \varepsilon_{o} \varepsilon^{\prime \prime} \tan \delta$. Where $\omega, \varepsilon_{0}, \varepsilon^{\prime \prime}$ are the angular frequency, dielectric permittivity of the free space and dielectric loss. The variation of real $\left(\sigma^{\prime}\right)$ and imaginary part $\left(\sigma^{\prime \prime}\right)$ of the complex conductivity as a function of frequency for PEO electrolyte with varying content of SN are shown in Figure 12 $\mathrm{a} \& \mathrm{~b}$. The plot infers the increase of ac conductivity with frequency and is divided in three regions (i) low frequency electrode-polarization region, (ii) frequency independent plateau region in intermediate frequency, and (iii) high-frequency dispersive region. In the low frequency ac conductivity increase with frequency and is result of dominance of the electrode polarization phenomena due to sufficient time to dipoles for orientation. The intermediate frequency plateau 
region is associated with the dc conductivity and implies the long-range ion migration. Then the high frequency dispersion region is observed corresponding to the ion migration by hopping mechanism i.e. short range ion migration. This switch from the intermediate region to dispersive region occurs at particular frequency i.e. hopping frequency $\left(\omega_{\mathrm{h}}\right)$. It may be noted that for pure PEO all three regions appears, but after addition of SN the high frequency dispersive region disappears. This implies that the $\omega_{\mathrm{h}}$ shifts toward the higher frequency with addition of SN. It rthe eflects that the ion migration in solid polymer electrolyte is the combined effect of the hopping process and segmental motion of polymer chains [71-74]. To obtain more crucial information the complex conductivity plot is fitted by the equation proposed by Roy et al., [75] which also included the universal Jonscher power law which provides details only of the high frequency region. So, we have fitted the ac conductivity plot in the whole frequency window, shown by solid line in the plot. The effective complex conductivity is expressed as by equation *

$$
\sigma_{e f f}^{*}=\left(\frac{1}{\sigma_{b}}+\frac{1}{i \omega C_{d l}}\right)^{-1}+i \omega C_{b}
$$

As the real part of the conductivity is given as equation *

$$
\sigma^{\prime}(\omega)=\frac{\sigma_{b}^{2} C_{d l} \omega^{\alpha} \cos \left(\frac{\alpha \pi}{2}\right)+\sigma_{b}\left(C_{d l} \omega^{\alpha}\right)^{2}}{\sigma_{b}^{2}+2 \sigma_{b} C_{d l} \omega^{\alpha} \cos \left(\frac{\alpha \pi}{2}\right)+\left(C_{d l} \omega^{\alpha}\right)^{2}}
$$

While in the high frequency, window equation is expressed as;

$$
\sigma^{\prime}(\omega)=\sigma_{b}\left[1+\left(\frac{\omega}{\omega_{h}}\right)^{n}\right]
$$

Where, all parameters have the same meaning as earlier and ' $n$ ' have a value less than unity. Here, $C_{d l}, \omega, s, \alpha, C_{b}$ are the frequency independent double layer capacitance, angular frequency, exponent terms ( <1) and bulk capacitance of the prepared solid polymer electrolyte. The $\sigma_{b}$ in Eq. 11 was replaced by Eq. 12 and was used to fit the real part of complex conductivity. 


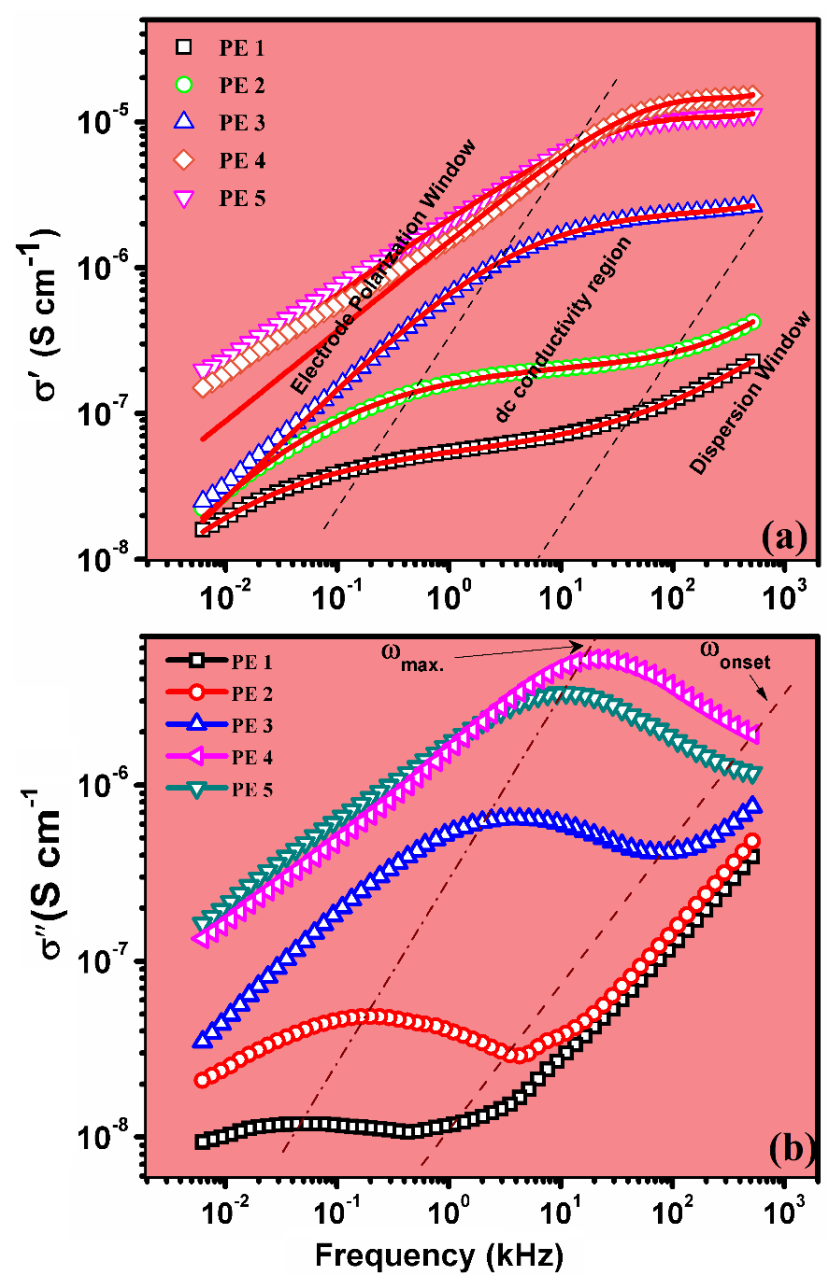

Figure 12. Frequency dependent (a) real part $\left(\sigma^{\prime}\right)$, and (b) Imaginary part $\left(\left(\sigma^{\prime \prime}\right)\right.$ of complex conductivity for solid polymer electrolyte. Solid lines are absolute fit to experimental data points. The dotted line shows the change in $\omega_{\max }$ and $\omega_{\text {on }}$ with $\mathrm{SN}$ content.

Figure 12 a shows the fitted plot of frequency dependent conductivity in the whole frequency window (shown by solid line) using $\sigma_{\mathrm{b}}, \omega_{\mathrm{h}}, \alpha, \mathrm{n}$ as variable parameter. It may be noted that both the experimental and fitted plot are in good agreement with each other. The fitted parameters $\left(\sigma_{\mathrm{b}}\right.$, $\left.\omega_{\mathrm{h}}, \alpha, n\right)$ are summarized in the Table 6 at room temperature. It may observed from the Table 6 that, hopping frequency $\left(\omega_{\mathrm{h}}\right)$ increase when salt is added in the pure PEO and increases further addition of SN. The high hopping frequency for the PE4 suggests the higher dc conductivity due to lowering of hopping relaxation time $\left(\tau_{\mathrm{h}}\right)$ for this system and is in agreement with the impedance study [75]. The increase in the conductivity is also related to increase in the disorder in the polymer chain arrangement after $\mathrm{SN}$ addition. For further strengthening the result, a correlation of various 
fitted parameters has been built in the upcoming section with the Ionic conductivity. This suggests that addition of SN increases the polymer flexibility and hopping of cation from one coordinating site is faster. For, $\omega>\omega_{\mathrm{h}}$, the two process may occur, (i) correlated forward-backward-forward hopping (unsuccessful hopping), and (ii) ion migration to the new coordinating site (successful hopping) [76-77]. The correlated forward-backward-forward hopping reflects the insufficient time to the cation to move to next coordinating site and results in dispersion in the high frequency window. It is also noted that, value of both exponent parameters is less than unity.

Table 6. Comparison of fitted parameters for real part of the complex conductivity for different PEs at RT.

\begin{tabular}{|c|c|c|c|c|c|c|}
\hline \multicolumn{2}{|c|}{ The real part of complex conductivity $\left(\boldsymbol{\sigma}^{\mathbf{}}\right)$} \\
\hline Sample Code & $\boldsymbol{\sigma}_{\mathbf{b}}\left(\times \mathbf{1 0}^{-\mathbf{6}} \mathbf{S ~ c m}^{-\mathbf{1}}\right)$ & $\boldsymbol{\omega}_{\mathbf{h}}\left(\times \mathbf{1 0}^{\mathbf{5}}\right)$ & $\boldsymbol{\alpha}$ & $\mathbf{n}$ & $\mathbf{C}_{\mathbf{d l}}(\boldsymbol{\mu F})$ & $\boldsymbol{\tau}_{\mathbf{h}}(\boldsymbol{\mu s})$ \\
\hline PE 1 & 0.05 & 0.52 & 0.57 & 0.48 & 0.02 & 19.1 \\
\hline PE 2 & 0.22 & 3.71 & 0.85 & 0.47 & 0.03 & 2.69 \\
\hline PE 3 & 0.95 & 8.13 & 0.38 & 0.77 & 1.66 & 1.23 \\
\hline PE 4 & 1.42 & 15.17 & 0.26 & 0.79 & 21.1 & 0.65 \\
\hline PE 5 & 1.12 & 9.13 & 0.31 & 0.98 & 14.2 & 1.09 \\
\hline
\end{tabular}

The frequency dependent imaginary part $\left(\boldsymbol{\sigma}^{\prime \prime}\right)$ of the complex conductivity is shown in Figure 12 b. The plot is divided in the region depending on two frequencies, onset frequency $\left(\omega_{o n}\right)$ and maximum frequency $\left(\omega_{\max }\right)$, (i) low frequency electrode polarization (EP) region, (ii) intermediate frequency dc conductivity region and (iii) high-frequency dispersion region. It may be observed from the plot that as we move from right to left on frequency axis, the decrease in the $\sigma^{\prime \prime}$ occurs and a minima $\sigma^{\prime \prime}$ is associated with the onset frequency $\left(\omega_{o n}\right)$ linked with onset of electrode polarization. At this frequency electrode polarization starts to build up and on moving toward decreasing frequency, maxima in $\sigma^{\prime \prime}$ is observed associated with the maximum frequency $\left(\omega_{\max }\right)$. It implies that, at this frequency maximum polarization is achieved [77, 78-80]. It is also observed $\sigma^{\prime}$ starts decreasing when the maxima in $\sigma^{\prime \prime}$ is observed as evidenced form the Figure $12 \mathrm{a} \& \mathrm{~b}$. Also, the polarization region in the Figure $12 \mathrm{~b}$ is wider for $\mathrm{SN}$ doped polymer salt matrix as compared to the SN free i.e. polymer salts matrix. It may be concluded that the addition of SN plays effective rile in enhancing the dielectric properties and cation migration in the solid polymer electrolyte. 


\subsection{Modulus Study}

The suppressed electrode polarization region in the complex permittivity is analyzed by using the modulus formalism in the whole frequency window. The modulus data is expressed in terms of reciprocal of complex permittivity and is expressed as

$$
\begin{gathered}
M^{*}=\frac{1}{\varepsilon^{*}}=M^{\prime}+j M^{\prime \prime} \\
M^{\prime}=\frac{\varepsilon^{\prime}}{\varepsilon^{\prime 2}+\varepsilon^{\prime \prime 2}} \text { and } M^{\prime \prime}=\frac{\varepsilon^{\prime \prime}}{\varepsilon^{\prime 2}+\varepsilon^{\prime \prime 2}}
\end{gathered}
$$

Figure 13 a-d shows the plot of $\mathrm{M}^{\prime \prime}$ vs. $\mathrm{M}^{\prime}$ for pure $\mathrm{PEO}, \mathrm{PEO}-\mathrm{NaPF}_{6}$, and PEO-NaPF 6 with different SN. The presence of single semi-circle in the plot implies that the present solid polymer electrolyte system shows single relaxation. All plots show a semicircle which is an indication of the single relaxation process and diameter depicts the storage capacity of the system. It is noted that the polymer electrolyte system PE3 shows the smaller diameter and it suggests that this system has large capacitance associated with it. This increase in the capacitance is due to the availability of a sufficient number of charge carriers owing to better salt dissociation in cation/anions. This highest capacitance has been observed from the impedance study also.
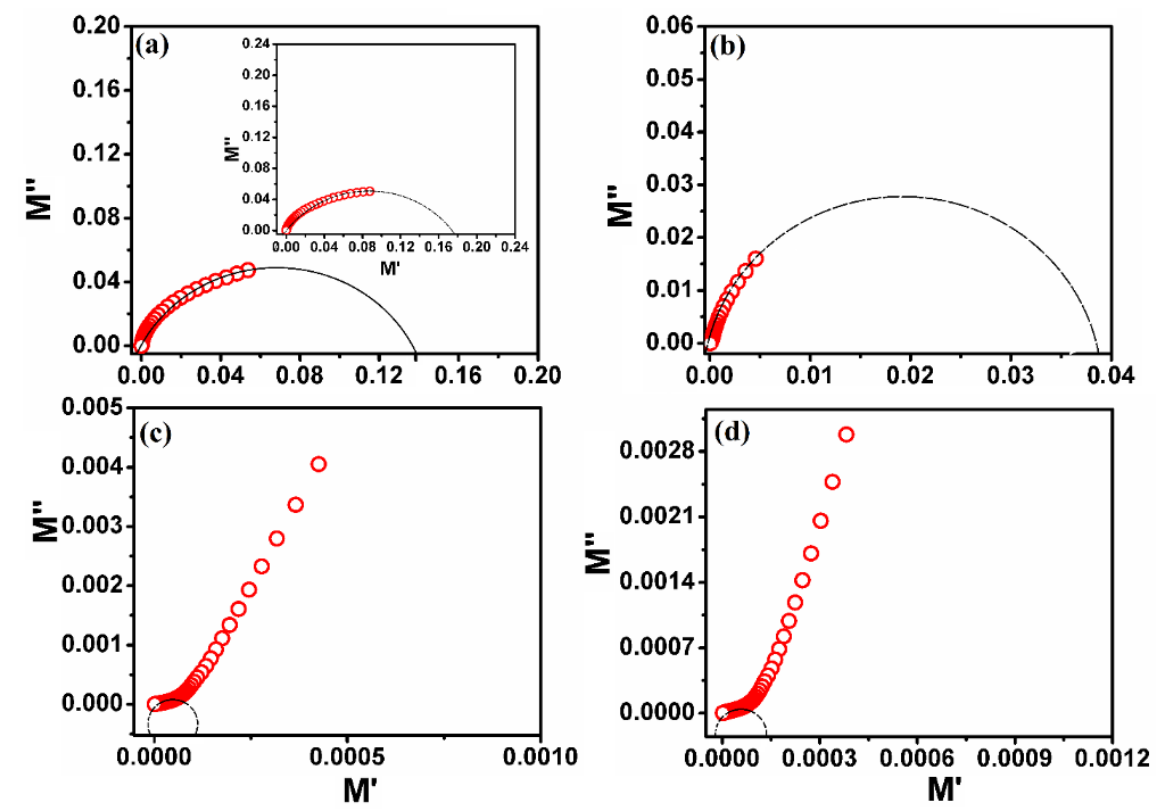

Figure 13. Argand plot of $\mathrm{M}^{\prime \prime}$ vs. $\mathrm{M}^{\prime}$ for (a) PE 2, (b) PE 3, (c) PE 4, (d) PE 5 at room temperature. (PE 1 is shown in inset)

\subsubsection{Real and Imaginary part of Modulus}


Figure $14 \mathrm{a} \& \mathrm{~b}$ shows the variation of the real $\left(M^{\prime}\right)$ and imaginary $\left(M^{\prime \prime}\right)$ parts of complex modulus against the frequency. A long tail is observed in the low frequency window corresponding to $M^{\prime} \rightarrow$ 0 and increase in the length of tail evidenced the large capacitance associated with electrodes ${ }^{[81] .}$ A similar result has been reported by Arof et al., [22]. At high frequency sharp increase in the Figure $14 \mathrm{a} \& \mathrm{~b}$, indicates the dispersion region owing to the low probability of ion responding to applied field [31, 83-84]. The peak was not observed in the plot and shift right toward the frequency limit of the instrument. The rapid increase in the Figure $14 \mathrm{~b}$ at high frequency is attributed to the ion hopping from one coordinating site to another. The lower value in modulus spectra $\left(M^{\prime \prime}\right)$ as in Figure $14 \mathrm{~b}$ is an indication of fast ion migration and is evidenced by the modulus relaxation time $\left(\tau_{\mathrm{m}}\right)$ that shows minima for the PE4 system. The lowering of the relaxation time reflects the highest ionic conductivity for this system [85]. Further, the real $\left(C^{\prime}\right)$ and imaginary $\left(C^{\prime \prime}\right)$ part of the capacitance are obtained using the equation;

$$
\text { As } C^{\prime}(\omega)=\frac{Z^{\prime \prime}}{\omega(|Z(\omega)|)^{2}} \text { and } C^{\prime \prime}(\omega)=\frac{Z^{\prime}}{\omega(|Z(\omega)|)^{2}}
$$

Here, $Z^{\prime}$ and $Z^{\prime \prime}$ are the real and imaginary part of impedance and $\omega$ is angular frequency $(=2 \pi f)$. Real part of capacitance indicates the storage of ions while imaginary part is associated with the energy loss in the polymer electrolyte [86]. The variation of the real and imaginary part of capacitance is shown on Figure $14 \mathrm{c} \& \mathrm{~d}$. For, all the solid polymer electrolytes, the real and imaginary part of capacitance decreases with frequency. Figure $14 \mathrm{c} \& \mathrm{~d}$ depicts the plot of real and imaginary part of capacitance against the frequency. It is observed that the both component shows decreasing trend with an increase of the frequency. The addition of SN in the polymer salt matrix increases the ions in the polymer matrix that contributed to capacitance and highest capacitance is observed for the PE4 system. 

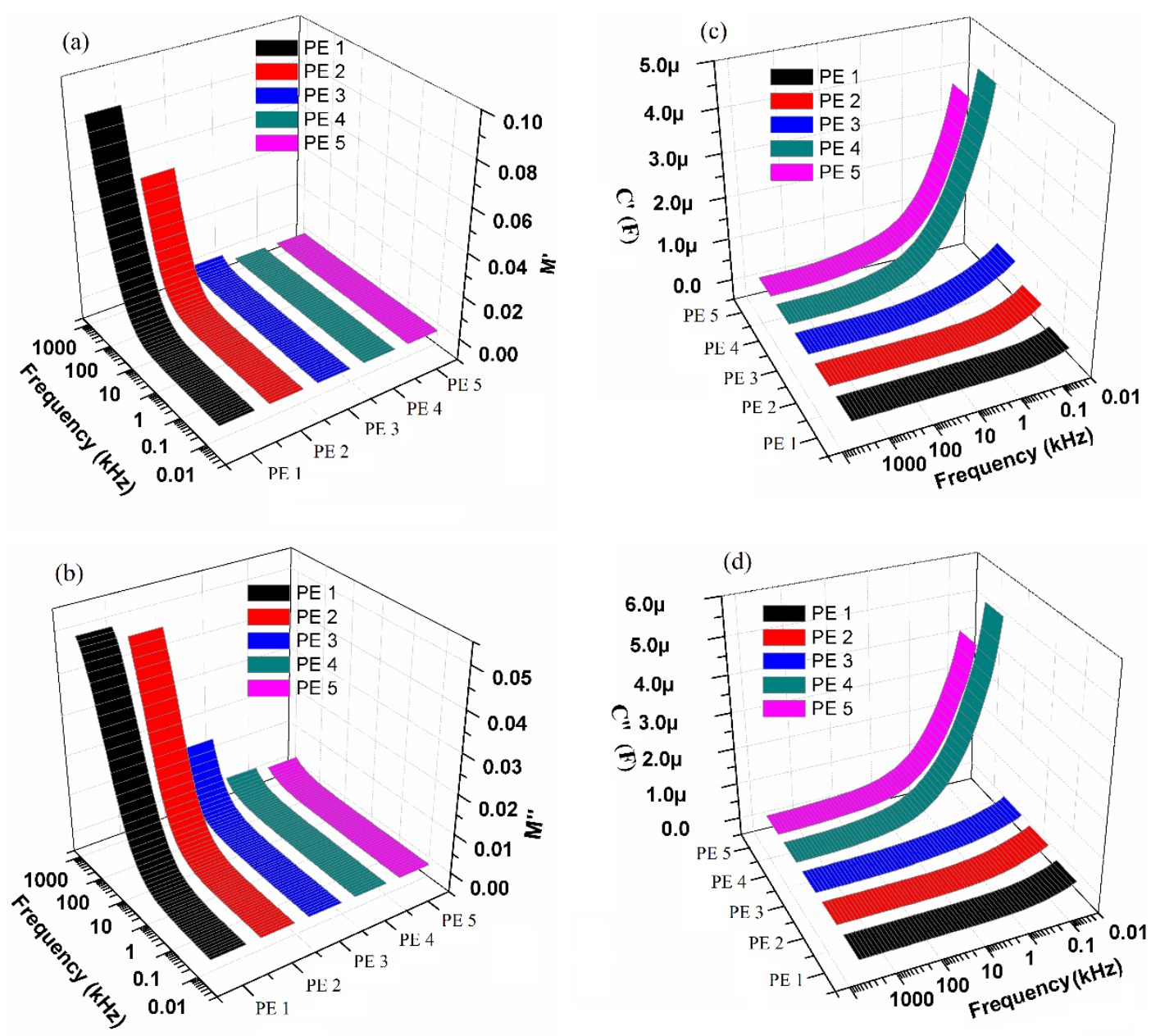

Figure 14. Frequency-dependent (a) real part of the modulus $\left(\mathrm{M}^{\prime}\right)$, (b) imaginary part of the modulus $\left(\mathrm{M}^{\prime \prime}\right)$, (c) real part of capacitance $\left(\mathrm{C}^{\prime}\right)$ and $(\mathrm{d})$ imaginary part of capacitance $\left(\mathrm{C}^{\prime \prime}\right)$ real of modulus spectra for various PEs at room temperature.

\subsection{Correlation of ionic conductivity $(\sigma)$ with double layer capacitance $\left(C_{d l}\right)$, and various relaxation times $\left(\tau_{\varepsilon^{\prime}}, \tau_{M}, \tau_{h}\right)$}

It was concluded from the above discussion that the ionic conductivity is linked with the relaxation time, number of charge carriers. So, correlation of the ionic conductivity is built-up with relaxation time $\left(\tau_{\varepsilon^{\prime}}, \tau_{M}, \tau_{h}\right)$ obtained by a different process (Figure 15). Figure 15 a shows the variation of ionic conductivity with SN content and shows maxima for $10 \mathrm{wt}$ \% SN content. This maximum may be due to the increase in the number of ions participating in the conduction. It reflects the crucial role played by the $\mathrm{SN}$ on altering the polymer matrix and the polymer flexible that promotes the faster ion migration from one coordinating site to another. While at high SN content decrease in the conductivity is due to the dominance of the plastic nature which shows a negative effect. 

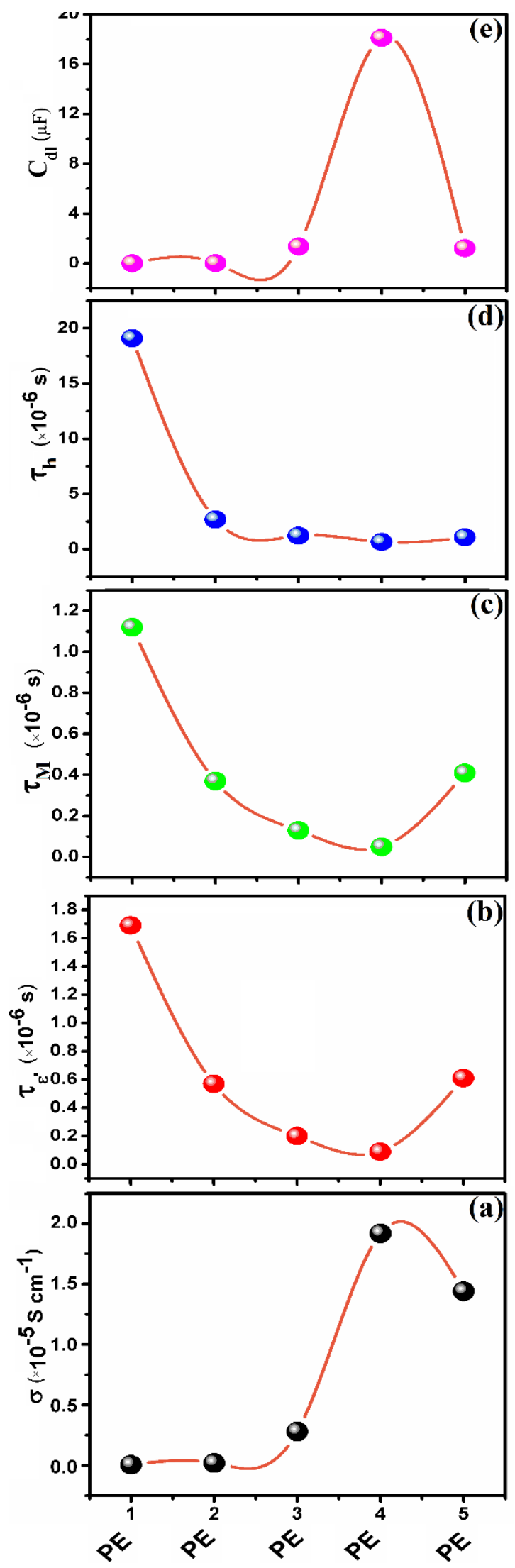

Figure 15. Correlation of ionic conductivity $(\sigma)$ with double layer capacitance $\left(\mathrm{C}_{\mathrm{dl}}\right)$, and various relaxation times $\left(\tau_{\varepsilon^{\prime}}, \tau_{M}, \tau_{h}\right)$. 
the polymer flexible that promotes the faster ion migration from one coordinating site to another. While at high SN content decrease in the conductivity is due to the dominance of the plastic nature which shows a negative effect. Figure $15 \mathrm{~b} \& \mathrm{~d}$ shows the variation of the relaxation time (dielectric relaxation time, molecular relaxation time, hopping time) against the SN content. It may be noted that the optimized system (PE4) shows minima in all relaxation time. The lowering of the relaxation time implies that at this content maximum number of ions are available for migration, as well as faster chain segmental motion is observed due to reduced viscosity of polymer chains. It can be concluded that the decrease of all three relaxation time with the addition of SN confirms The variation of the double layer capacitance with SN content is shown in Figure 15 e and is maximum for the PE4 system. As capacitance is related with the storage capacity of ions, so it suggests that the present system have a large number of free ions. In conclusion, it may be stated that the lowering of the relaxation time and maxima in the ionic conductivity is result of the presence of the polar nitrile group in the SN. All results are in absolute correlation with each other.

\subsection{Ion Transport Mechanism}

To understand the role of the $\mathrm{SN}$ in improving the properties of the polymer matrix, an ion transport scheme is proposed. The constituents of the solid polymer electrolyte are PEO, NaPF6, and SN. Figure 16 a shows the pure PEO chains and are crystalline in nature. Now, when salt is added in the pure PEO then the salt get dissociated in the cation (red circle) and anion (yellow circle). Two possible interactions exists here, (i) As cation $\left(\mathrm{Na}^{+}\right)$is Lewis acid, it has tendency to coordinate to the ether group of the polymer chain, and (ii) as anion $\left(\mathrm{PF}_{6}{ }^{-}\right)$is bulky in size, it remains in immobilized state and attached with the polymer backbone (Figure $16 \mathrm{~b}$ ). This makes polymer salt complexation as evidenced by the FTIR analysis. Now, when SN is added to the polymer salt matrix. Now, when the addition of SN is done in polymer salt matrix, then the presence of highly polar nitrile group $(\mathrm{C} \equiv \mathrm{N})$ in the $\mathrm{SN}$ alters the significant interaction between the polymer and salt. Two possibilities are, (i) cation coordination with ether group of PEO, and (ii) cation coordination with nitrile group. But, cation has more tendency to interact with ether group than nitrile due to high electronegativity of oxygen as compared to nitrogen. As another key effect of SN is that it may penetrate in between the polymer chains and disrupt the covalent bonding between them. It results in the enhanced free volume for the ion migration and promotes the faster ion migration (Figure 16 c \& d) by reducing the viscosity of polymer chains. Same has been evidenced by the XRD analysis. 


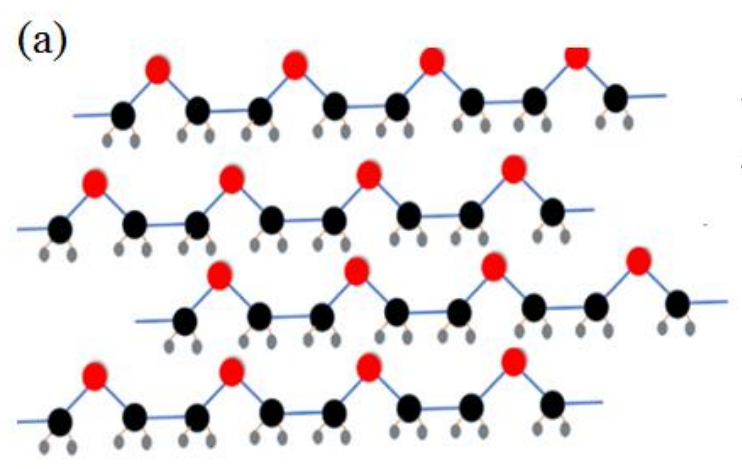

PEO chain having covalent bonding inbetween

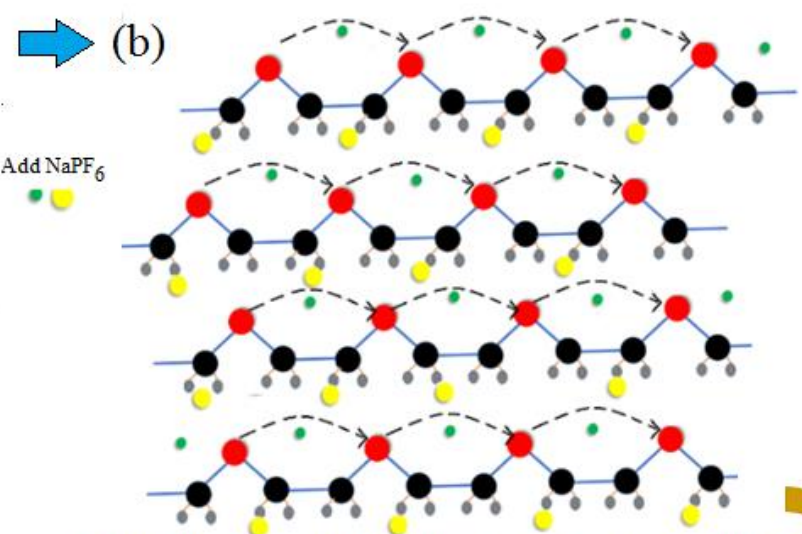

Anion interaction with methyl group and cation with ether group (disruption of covalent bondng and release of free cation)

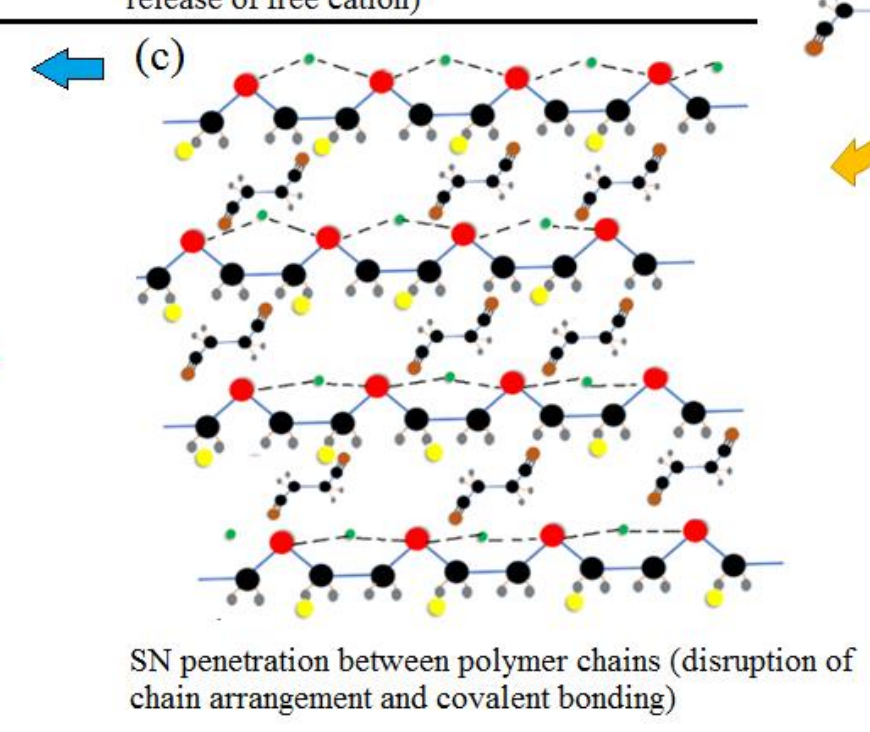

SN penetration between polymer chains (disruption of chain arrangement and covalent bonding) (d)

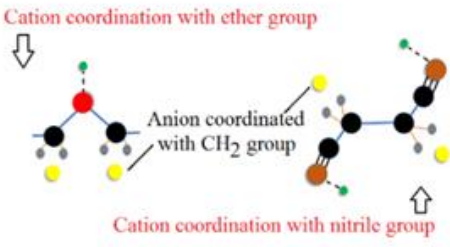

Two remarkable intercation for cation

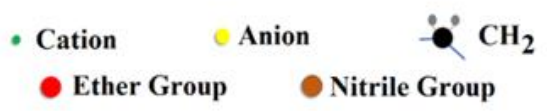

Two competitive interaction of cation

1. with nitrile group of $\mathrm{SN}$

2. with ether group of PEO

Figure 16. Proposed scheme for the cation transport, (a) pure PEO polymer chain, (b) cation coordination with PEO, (c) interaction between nitrile group of SN, PEO and cation and (d) two competitive interaction of cation.

\section{Conclusions}

The effect of $\mathrm{SN}$ on the structural, electric and dielectric properties in $\mathrm{PEO}-\mathrm{NaPF}_{6}+\mathrm{SN}$ based solid polymer electrolyte prepared by solution cast technique has been investigated. The morphological, structural, electrochemical and dielectric properties were investigated in detail. The XRD analysis suggests the enhancement of the amorphous content on the addition of SN and is supported by the FESEM analysis. The complex formation was confirmed by the FTIR and interactions between the polymer, salt are influenced by the $\mathrm{SN}$ addition. The highest ionic conductivity has been found to be $1.92 \times 10^{-5} \mathrm{~S} \mathrm{~cm}^{-1}$ (@RT) for the $10 \mathrm{wt}$ \% $\mathrm{SN}$ doped (PE4) solid polymer electrolyte. The ion transference number was close to unity for all systems (0.99), and voltage stability window 
was about $4 \mathrm{~V}$ which lies in the desirable limit for the solid state battery applications. The dielectric properties of the prepared polymer electrolyte were studied in detail. The polymer electrolyte system with highest ionic conductivity (PE4) has highest dielectric constant and suggests the high storage capacity. The real part of ac conductivity has been analyzed in the whole frequency window including the low-frequency electrode polarization region and high-frequency dispersion region. The optimized system having high conductivity shows the lowest relaxation time $\left(\tau_{\varepsilon^{\prime}}\right.$, $\left.\tau_{\mathrm{M}}, \tau_{\mathrm{h}} ; 10^{-6} \mathrm{~s}\right)$. The modulus spectra evidence the presence of single relaxation and increased capacitance. The ionic conductivity shows one-to-one correspondence with the relaxation time and double layer capacitance and confirms the PE4 as an optimized system. Finally, an ion transport scheme has been proposed to highlight the role of SN in modifying the interactions between polymer and salt.

\section{Acknowledgment}

One of the authors (AA) thankfully acknowledges the Central University of Punjab, Bathinda for providing the fellowship.

\section{References:}

1. B. L. Ellis, L. F. Nazar, Curr Opin Solid State Mater Sci. 2012, 16, 168-177.

2. H. Che, S. Chen, Y. Xie, H. Wang, K. Amine, X. Z. Liao, Z. F. Ma, Energy Environ Sci. 2017, 10, 1075-1101.

3. H. K. Koduru, L. Marino, F. Scarpelli, A. G. Petrov, Y. G. Marinov, G. B. Hadjichristov, ...N. Scaramuzza, Current Applied Physics 2017, 17, 1518-1531.

4. Q. Bai, L. Yang, H. Chen, Y. Mo, Advanced Energy Materials 2018, 1702998

5. A. Arya, A. L. Sharma, Applied Science Letters 2016, 2, 72-75.

6. D. K. Pradhan, B. K. Samantaray, R. N. P. Choudhary, A. K. Thakur, Ionics 2005, 11, 95102.

7. H. M. J. C. Pitawala, M. A. K. L. Dissanayake, V. A. Seneviratne, B. E. Mellander, I. Albinson, J Solid State Electrochem 2008, 12, 783-789.

8. A. Arya, M. Sadiq, A. L. Sharma, Ionics 2018. DOI: 10.1007/s11581-017-2364-7

9. A. L. Sharma, A. K. Thakur, Ionics 2013, 19, 795-809.

10. A. Arya, A. L. Sharma, Ionics 2017, 23, 497-540.

11. S. K. Chaurasia, S. Kataria, A. K. Gupta, Y. L. Verma, V. K. Singh, A. K. Tripathi, A. L. Saroj, R. K. Singh, RSC Adv. 2014, 5, 8263-8277.

12. C. Bhatt, R. Swaroop, A. Arya, A. L. Sharma, Journal of Materials Science and Engineering B 2015, 5, 418-434.

13. S. M. Tan, M. R. Johan, Ionics 2011, 17, 485-490.

14. A. Arya, A. L. Sharma, J. Phys. D: Appl. Phys 2018, 21, 045504.

15. A. L. Sharma, A. K. Thakur, J Mater Sci 2011, 46, 1916-1931. 
16. P. Joge, D. K. Kanchan, P. Sharma, N. Gondaliya, Indian journal of pure and applied physics 2013, 50, 350-353

17. D. Bresser, S. Passerini, B. Scrosati, Chem Commun. 2013, 49, 10545-10562.

18. A. Arya, A. L. Sharma, J. Phys. D: Appl. Phys. 2017, 50, 443002.

19. Y. Xue, X. Li, D. J. Quesnel, International Journal Of Electrochemical Science 2017, 12, 10674-10686.

20. A. Laheäär, A. Jänes, E. Lust, Electrochimica Acta 2012, 82, 309-313

21. A. Arya, A. L. Sharma, Journal of Solid State Electrochemistry 2018, 1-21.

22. P. J. Alarco, Y. Abu-Lebdeh, A. Abouimrane, M. Armand, Nature Materials 2004, 3, 476.

23. V. Aravindan, C. Lakshmi, P. Vickraman, Current Applied Physics 2009, 9, 1106-1111.

24. K. Karuppasamy, D. Kim, Y. H. Kang, K. Prasanna, H. W. Rhee, Journal of Industrial and Engineering Chemistry 2017, 52, 224-234.

25. S. A. Hashmi, H. M. Upadhyaya, A. K. Thakur, A. L. Verma, Ionics 2000, 6, 248-259,

26. A. Das, A. K. Thakur, K, Kumar, Ionics 2013, 19, 1811-1823.

27. Choudhary, R. J. Sengwa, Mater Chem Phys 2013, 142, 172-181.

28. S. A. Hashmi, S. Chandra, Mater Sci Eng B 1995, 34, 18-26.

29. C. Zhang, S. Gamble, D. Ainsworth, A. M. Slawin, Y. G. Andreev, P. G. Bruce, Nat Mater. 2009, 8, 580-584.

30. K. Kesavan, C. M. Mathew, S. Rajendran, M. Ulaganathan, Materials Science and Engineering: B 2014, 184, 26-33.

31. T. Mohamed Ali, N. Padmanathan, S. Selladurai, Ionics 2013, 19, 1115-1123.

32. C. V. Subba Reddy, A. K. Sharma, V. V. R. Narasimha Rao, J Power Sources 2003, 114, 338-345.

33. B. Jinisha, K. M. Anilkumar, M. Manoj, V. S. Pradeep, S. Jayalekshmi, Electrochimica Acta. 2017, 235, 210-222.

34. P. S. Anantha, K. Hariharan, Solid State Ionics 2005, 176, 155-162.

35. A. K. Jonscher. Dielectric Relaxation in Solids. Chelsea Dielectric, London, 1983.

36. R. Tang, C. Jiang, W. Qian, J. Jian, X. Zhang, H. Wang, H. Yang, Sci Rep. 2015, 5, 13645.

37. A. Arya, A. L. Sharma, S. Sharma, M. Sadiq, Journal of Integrated Science and Technology 2016, 4, 17-20.

38. A. L. Sharma, A. K. Thakur, J Appl Polym Sci. 2010, 118, 2743-2753.

39. S. Kim, E. J. Hwang, S. J. Park, Curr Appl Phys. 2008, 8, 729-731.

40. A. Rai, A. L. Sharma, A. K. Thakur, Solid State Ionics 2014, 262, 230-233.

41. M. M. E. Jacob, S. R. S. Prabaharan, S. Radhakrishna, Solid State Ionics 1997, 104, $267-$ 276 ,

42. M. Hema, P. Tamilselvi, Journal of Physics and Chemistry of Solids 2016, 96, 42-48.

43. A. L. Sharma, N. Shukla, A. K. Thakur, J Polym Sci Part B Polym Phys. 2008, 46, 25772592.

44. J. B. Wagner, C. J. Wagner, Chem. Rev. 1957, 20, 1597-1602.

45. J. Evans, C. A. Vincent, P. G. Bruce, Polymer 1987, 28, 2324-2328. 
46. P. B. Bhargav, V. M. Mohan, A. K. Sharma, V. V. R. N. Rao, Curr Appl Phys. 2009, 9, $165-171$.

47. A. Arya, A. L. Sharma Journal of Physics D: Applied Physics 2018, 51, 045504.

48. M. Faridi, L. Naji, S. Kazemifard, N. Pourali, Chemical Papers 2018, 1-12.

49. S. V. Shalu, R. K. Singh, J Mater Chem C 2015, 3, 7305-7318

50. L. Balo, H. Gupta, V. K. Singh, R. K. Singh, Electrochimica Acta 2017, 230, 123-131

51. C. C. Yang, Journal of Power Sources 2002, 109, 22-31.

52. S. Schrodle, G. Annat, D.R. MacFarlane, M. Forsyth, R. Buchner, G. Hefter, Aust J Chem. 2007, 60, 6-8.

53. E.I. Izgorodina, M. Forsyth, D.R. MacFarlane, Phys Chem Chem Phys. 2009, 11, 2452.

54. A. Arya, S. Sharma, A. L. Sharma, Dinesh Kumar, M. Sadiq, Asian J Eng and App Tech, 2016, 5, 4-7

55. K. S. Cole, R. H. Cole, J Chem Phys. 1941, 9, 341-351.

56. A. L. Sharma, A. K. Thakur, Ionics 2009, 16, 339-350.

57. V. T. Truong, A. R. Codd, M. Forsyth, J Mater Sci. 1994, 29, 4331-4338.

58. A. L. Sharma, A. K. Thakur, Ionics 2015, 21, 1561-1575.

59. R. J. Sengwa, K. Kaur, R. Chaudhary, Polymer International 2000, 49, 599-608.

60. E. M. Abdelrazek, I. S. Elashmawi, A. M. Hezma, A. Rajeh, M. Kamal, Physica B: Condensed Matter 2016, 502, 48-55.

61. M. Ravi, S. Song, K. Gu, J. Tang, Z. Zhang, Materials Science and Engineering: B 2015, 195, 74-83.

62. K. Gohel, D. K. Journal of Advanced Dielectrics 2018, 8, 1850005.

63. S. Choudhary, P. Dhatarwal, R. J. Sengwa, Indian Journal of Engineering and Material Sciences 2017, 24, 123-132.

64. M. Ravi, Y. Pavani, K. Kiran Kumar, S. Bhavani, A.K. Sharma, V.V.R. Narasimha Rao, Mater Chem Phys 2011, 130, 442-448

65. F. Salman, R. Khalil, H. Hazaa, Adv. J. Phys. Sc. 2014, 3, 1-9.

66. M. A. Morsi, S. A. El-Khodary, A. Rajeh, Physica B: Condensed Matter 2018, 539, 88-96

67. C. S. Prasanna, S. A. Suthanthiraraj, Ionics 2017, 23, 3137-3150.

68. R. J. Singh, Solid State Physics, Dorling Kindersley (India), 2012.

69. M. F. Shukur, F. M. Ibrahim, N. A. Majid, R. Ithnin, M. F. Z. Kadir, Physica Scripta 2013, 88, 025601.

70. Y. Z. Weia, S. Sridhar, J Chem Phys. 1993, 99, 3119-3124.

71. A. L. Sharma, A. K. Thakur, Ionics 2010, 17, 135-143.

72. S. Nasri, A. B. Hafsia, M. Tabellout, M. Megdiche, RSC Advances 2016, 6, 76659-76665.

73. A. K. Jonscher, J Mater Sci. 1978, 13, 553-562.

74. A. N. Papathanassiou, I. Sakellis, J. Grammatikakis, Appl Phys Lett. 2007, 91, 122911.

75. A. Roy, A.; B. Dutta, S. Bhattacharya, RSC Advances 2016, 6, 65434-65442.

76. N. Shukla, A. K. Thakur, A. Shukla, D.T. Marx, Int J Electrochem Sci. 2014, 9, 76447659.

77. A. Arya, A. L. Sharma Journal of Physics: Condensed Matter 2018, 30, 165402. 
78. Fuentes, A. Andrio, F. Teixidor, C. Vinas, V. Compan, Physical Chemistry Chemical Physics 2017, 19, 15177-15186.

79. A. A. Khamzin, I. I. Popov, R. R. Nigmatullin, Physical Review E - Statistical, Nonlinear, and Soft Matter Physics 2014, 89, 032303.

80. D. Fragiadakis, S. Dou, R. H. Colby, J. Runt, Macromolecules 2008, 41, 5723-5728.

81. R. Baskaran, S. Selvasekarapandian, G. Hirankumar, M. S. Ionics 2004, 10, 129-134.

82. H. J. Woo, S. R. Majid, A. K. Arof, Materials Chemistry and Physics 2012, 134, 755-761

83. A. Karmakar, A. Ghosh, Curr Appl Phys. 2012, 12, 539-543.

84. P. Dhatarwal, R. J. Sengwa, Journal of Polymer Research 2017, 24, 135.

85. P. B. Macedo, C. T. Moynihan, R. Bose, Phys Chem Glas. 1972, 13, 171-179.

86. M. Yadav, M. Kumar, T. Tiwari, N. Srivastava, Ionics 2016, 23, 2871-2880. 